\title{
Low-pressure diamond: from the unbelievable to technical products
}

\author{
Roland Haubner ${ }^{1}$ (1)
}

Received: 20 January 2021 / Accepted: 17 February 2021 / Published online: 16 March 2021

(c) The Author(s) 2021

\begin{abstract}
The idea to grow diamond from the gas phase was born in the 1950s but it took about 30 years until first diamond layers directly grown from the gas phase on substrates were shown in Japan by Matsumoto and co-workers. During the first years of research the function of atomic hydrogen, various growth methods and process parameters were investigated. Research was primarily focused on applications for wear-resistant tools. For this topic the interactions of substrates like hardmetals and ceramics, with diamond deposition gas atmosphere, were investigated. Beside its superior hardness, diamond exhibits the highest heat conductivity, high transparency, high chemical inertness and suitable semiconducting properties. The various requirements for the areas of application of diamond required a division of diamond research into corresponding sub-areas. The hot-filament method is used mainly for wear applications, because it is highly suited to coat complex geometries, but the diamond contains some impurities. Another method is the microwave plasma system which allows the growth of pure diamond used for optical windows and applications requiring high thermal conductivity. Other research areas investigated include doped diamond for microelectronic or electrochemical applications (e.g. waste water treatment); ballas (polycrystalline, spherical diamond), NCD (nanocrystalline diamond) and UNCD (ultra-nanocrystalline diamond) for wear applications. It should be noted that CVD (chemical vapour deposition) diamond synthesis has reached the stage of industrial production and several companies are selling different diamond products. This work is intended to convey to the reader that CVD diamond is an industrially manufactured product that can be used in many ways. With correspondingly low costs for this diamond, new innovative applications appear possible.
\end{abstract}

Keywords Diamond · CVD

\section{History}

Diamond synthesis was a miracle of nature for hundreds of years until scientists at GE (General Electric Company) succeeded in high-temperature high-pressure (HPHT) synthesis of diamond in 1954 [1]. This synthesis follows the rules of thermodynamics, and process parameters of diamond growth are located in the region of diamond stability.

However the research on diamond synthesis within the region of its thermodynamic metastability started nearly simultaneously, with patent applications in Russia and the USA [2, 3]. In Russia, Deryagin and Spitsyn [4, 5]

I dedicate this article to Mr. emer.O.Univ.Prof. Dipl.-Ing. Dr. Roland Stickler, on the occasion of his 90th birthday.

Roland Haubner

roland.haubner@tuwien.ac.at

1 TU Wien, Institute of Chemical Technologies and Analytics, Getreidemarkt 9/164-CT, 1060 Vienna, Austria investigated the growth of diamond from the gas phase on diamond seed crystals. With this method it was possible to increase the size of diamonds up to the onset of graphite growth, but it was necessary to use a cyclic process to remove graphite and non-diamond carbon. For the etching step, oxidising acids or hydrogen were used at increased pressure and temperature. At this time, Angus and co-workers investigated the use of atomic hydrogen (at.H) for etching graphite [6].

In principle the requirements for low-pressure diamond growth were known at this time. In Russia, Deryagin, Spitsyn and several co-workers investigated the epitaxial diamond growth on diamond also with etching graphite by atomic hydrogen [7-14]. All of these papers describe the diamond growth very vaguely, possibly for reasons of confidentiality.

Also during the late 1970s the deposition of carbon coatings by PVD (physical vapour deposition) was investigated. Because some of these coatings showed high 
hardness, Weissmantel called these coatings "diamondlike carbon" (DLC) [15-19]. This name immediately became accepted for amorphous carbon coatings.

The situation changed when Japanese researchers from NIRIM (National Institute for Research in Inorganic Materials, Tsukuba) published the low-pressure diamond deposition, using the hot-filament method, in detail in 1982 [20, 21]. Shortly after, papers about the characterisation of the diamonds and other deposition methods were published $[22,23]$.

Since it is impossible from a thermodynamic point of view to produce diamond under low-pressure conditions, it was unbelievable for chemists at the time that such a process is possible. Because Prof. B. Lux (1930-2013) [24] from TU Wien ignored thermodynamic prejudices and believed in the Japanese publications in 1984, lowpressure diamond research started in Austria. In July 1985, the first diamond crystals were grown in Vienna (Fig. 1) [25-27]. Their presence was confirmed by Raman measurements.

In Japan many research groups in companies but also at universities investigated various aspects of this new method of diamond growth. Outside of Japan, research on CVD diamond started a little later.

\section{Atomic hydrogen: the secret of low-pressure diamond growth}

For low-pressure diamond deposition, at.H is needed. The unbelievable fact was that from a thermodynamic point of view, it is impossible to grow diamond at low pressure. However in reality, atomic hydrogen is necessary for diamond growth and drives non-equilibrium reactions already resulting in diamond.

A filament bulb was used to illustrate how easy diamond deposition is (Fig. 2a). During the first years, the actual effect and contribution of atomic hydrogen was not clear, but Badzian et al. [28, 29] showed a plausible concept (Fig. 2b). During pyrolysis of carbon, the deposition of diamond is thermodynamically preferred, because it is metastable. However, in reality, graphite is formed owing to the Ostwald-Vollmer law [30], because graphite has a lower density than diamond. The etching of the layered $s p^{2}$ graphite crystal structure by atomic hydrogen is much faster than the etching of $s p^{3}$ diamond. By combination of pyrolysis and etching with atomic hydrogen, diamond can be grown directly. Atomic hydrogen has to be generated and transported to a substrate surface without recombination (Fig. 2c) [31].

Thermodynamic equilibrium calculations can be used to calculate the amount of at.H achievable at selected conditions of gas activation, but not to describe diamond
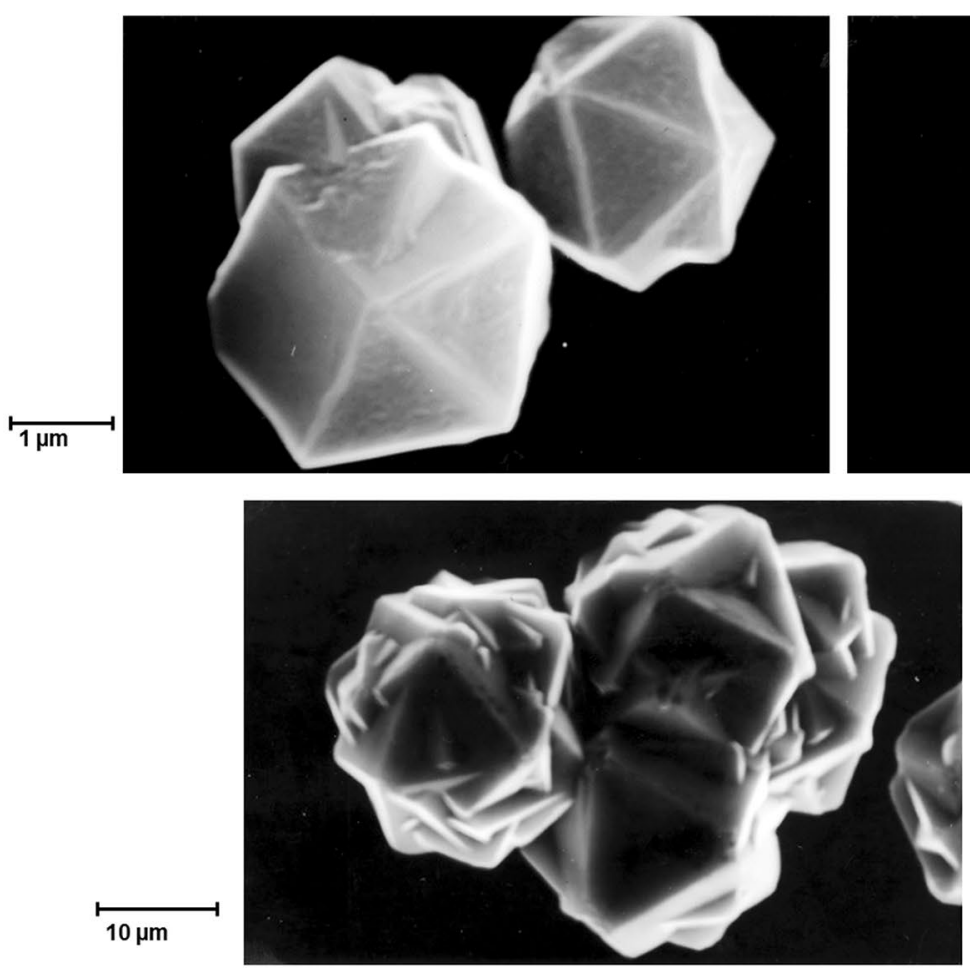
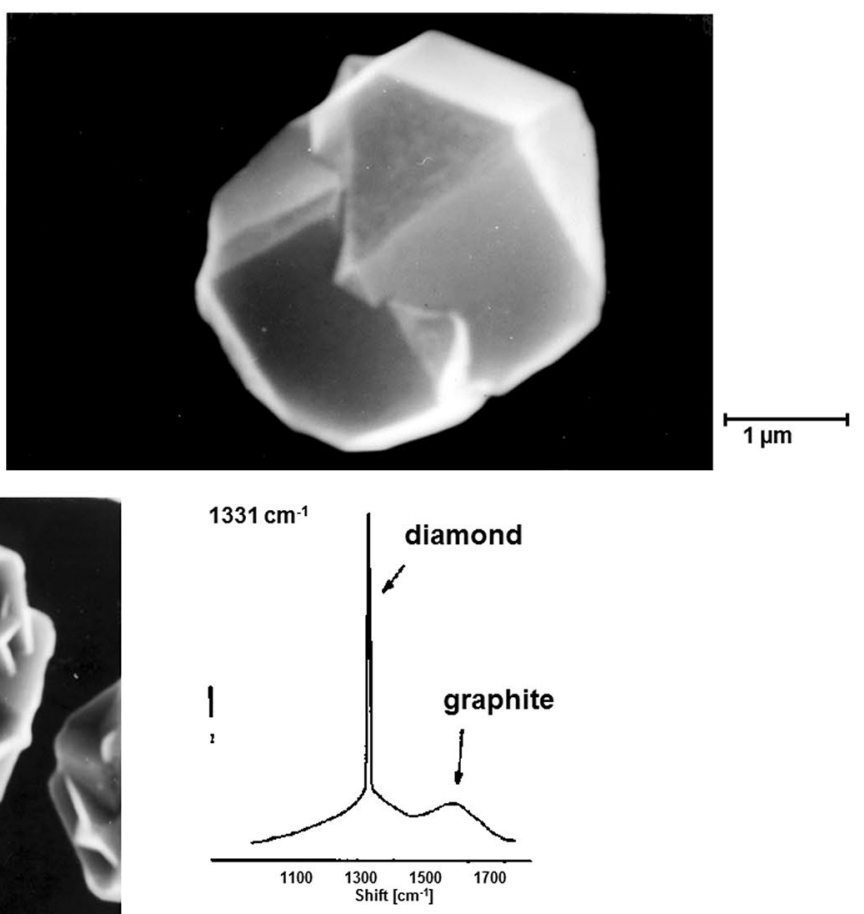

Fig. 1 First low-pressure diamond crystals grown by the hot-filament method at TU Wien in 1985 (modified from [25]) 
Fig. 2 Explanations of CVD diamond growth: a simplified demonstration of atomic hydrogen generation by a light bulb (modified from [47]), b selective etching of graphite by atomic hydrogen (modified from [28]), $\mathbf{c}$ influence of temperature and gas pressure on atomic hydrogen generation [46]

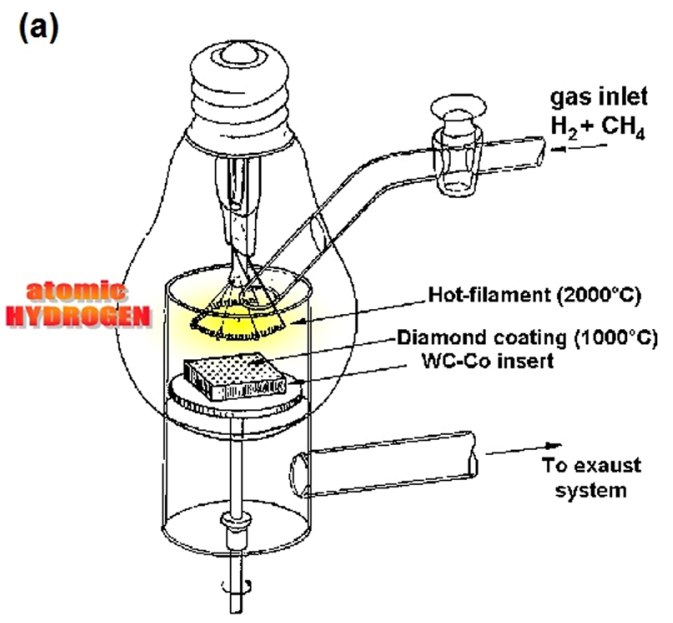

(b) pyrolysis

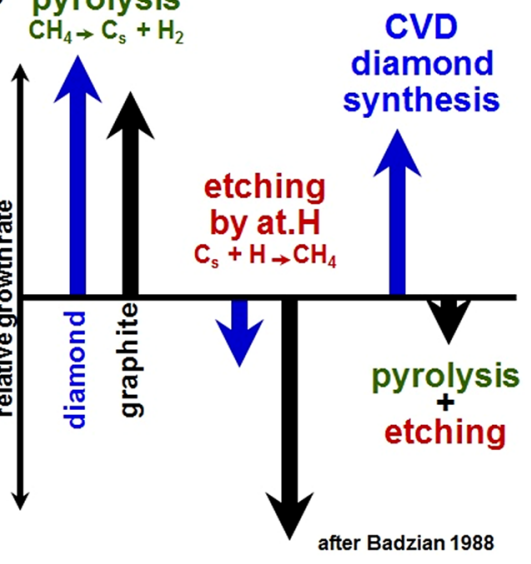

(c)

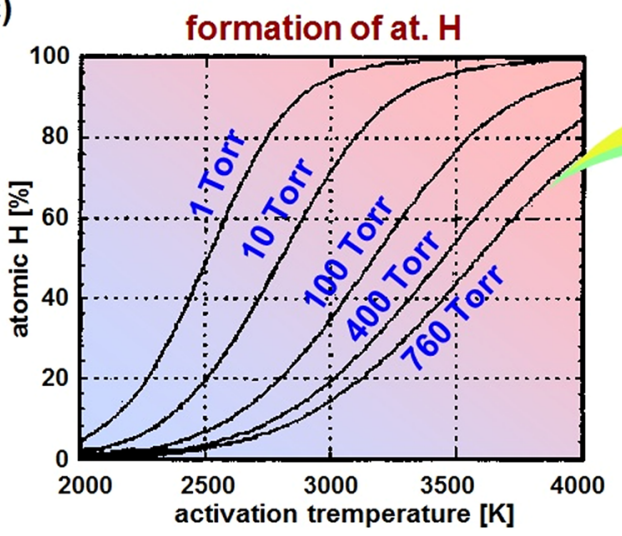

transport of at. $\mathrm{H}$ to the substrate

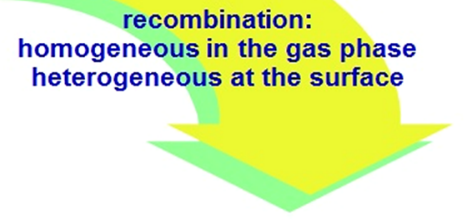

\section{at. $\mathrm{H}$ at the substrate permit} diamond growth growth. During gas activation of hydrogen and carboncontaining gas mixtures, many $\mathrm{C}_{x} \mathrm{H}_{y}$ compounds can be formed theoretically [32-35]. Kinetic calculations, considering the non-equilibrium system and continuous addition of atomic hydrogen, show the complexity of the chemical reactions (Fig. 3) [36, 37]. Later computer simulations were used to try to explain diamond growth and the role of at.H [38].
Fig. 3 Kinetic calculations in the $\mathrm{C} / \mathrm{H}$ system with additional at.H (modified from [36])

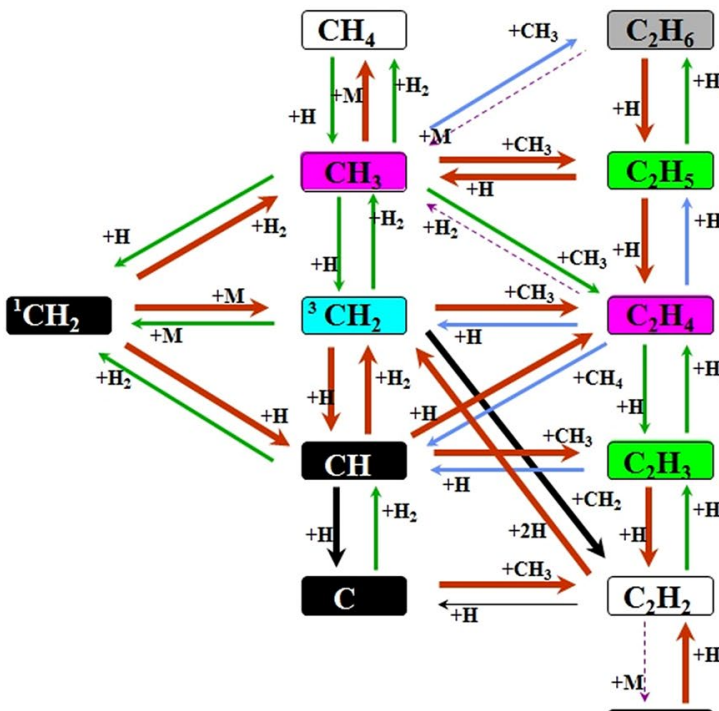
(exemplary for $900^{\circ} \mathrm{C}$,
42 mbar, $\mathrm{k}=0.3 / \mathrm{s}$ )

\section{Mole}

Mole fractions $\log (\mathrm{m} . \mathrm{f}$.)

\begin{tabular}{|l|l|}
$\log (\mathrm{m} . \mathrm{f})$. & $\log (\mathrm{k})$ \\
-4 to -3 & above 14 \\
-5 to -4 & 12 to 14 \\
-6 to -5 & 10 to 12 \\
-7 to -6 & 8 to 10 \\
& 6 to 8
\end{tabular}


(a) (111) crystals

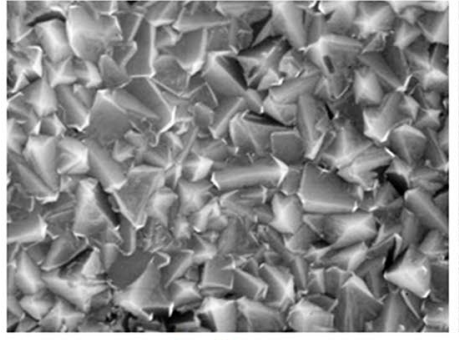

ballas

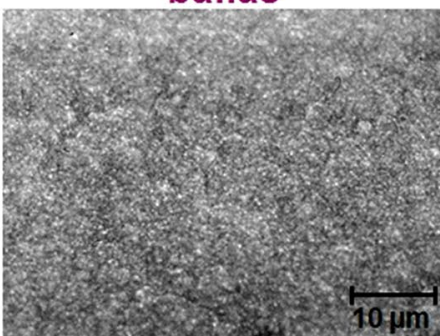

(100) crystals

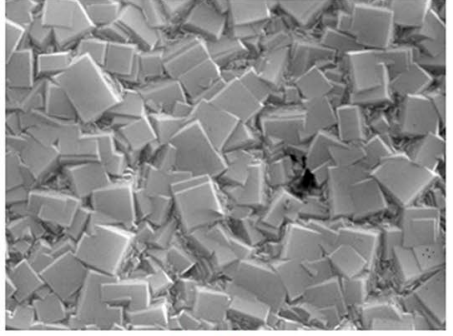

ballas

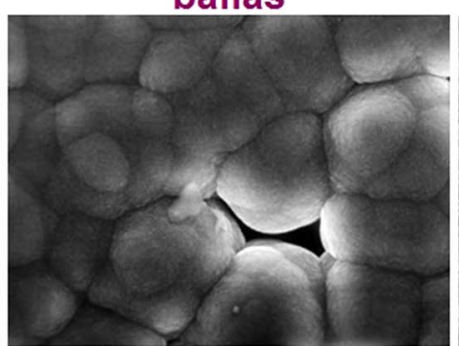

$(100)+$ ballas

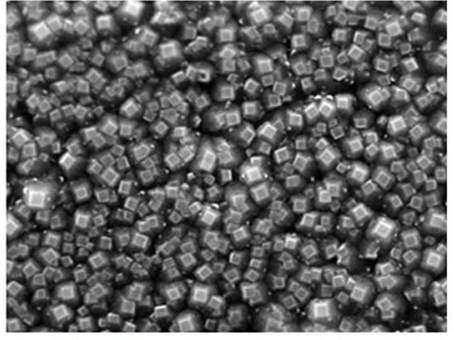

ballas + graphite

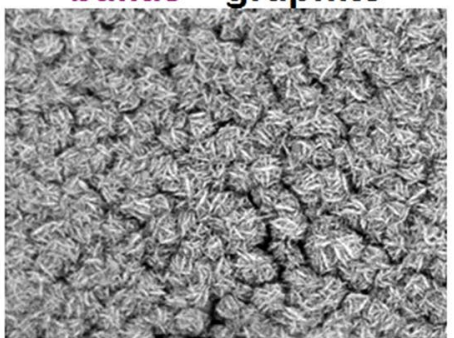

(b)

low

plasma intensity - at. hydrogen atomic hydrogen, surface temperature, gas pressure high
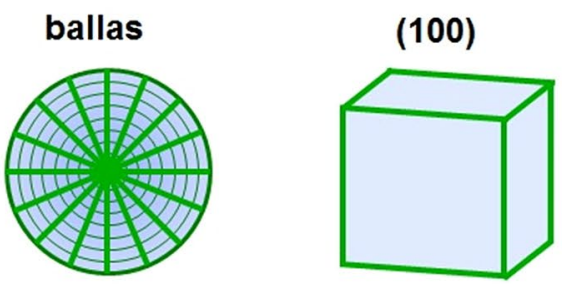

$(100) /(111)$

(111)
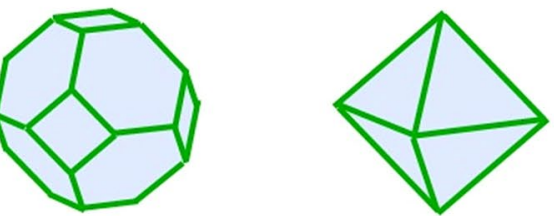

high

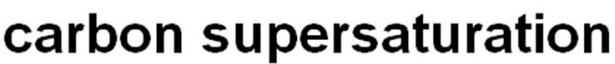

low methane concentration

(c) diamond crystals with perfect
crystal twinned and

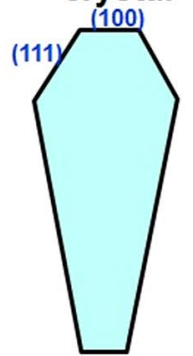

defect free area submicron areas
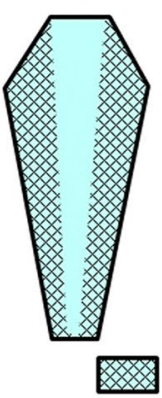

area with twins

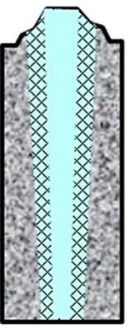

submicrontwined diamond

ballas containing graphitic lamellae
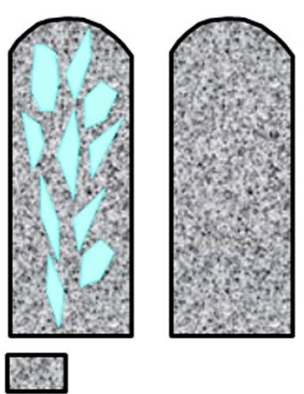

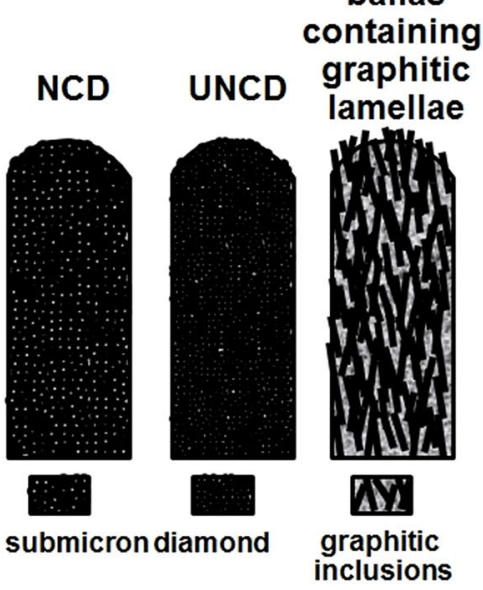


4Fig. 4 Relationship between the ratio of at.H and carbon on the resulting diamond morphologies observed (a) (modified from [40]), b schematic representation of the effect of at.H and carbon on diamond morphology (modified from [43-45]) (c) schematic representation of the defects distribution in deposited diamond in relation to the surface morphology

Finally, diamond morphology and quality are defined by the amount of at.H and its relation to carbon (Fig. 4). Diamond morphology changes from well-faceted octahedric (111) over cubic (100) to un-faceted ballas morphology with decreasing at.H to $\mathrm{C}$ ratio (Fig. 4a) [39, 40]. The term ballas for half-spherical and polycrystalline diamond deposits was first used by Bichler et al. [25, 27], but later cauliflower-like [41], ball-shape [42] etc. were used by some authors.

The relationships between deposition conditions, amount of at.H and diamond morphology are shown in Fig. $4 \mathrm{~b}$ [43-47].

\section{Methods to generate atomic hydrogen for diamond growth}

Low-pressure diamond deposition is a CVD process, using hydrocarbons and at.H for diamond growth. The at.H can be produced by high temperatures or gas plasma (Fig. 5). These methods offer the possibility of growing polycrystalline diamond layers in large size and thickness on different substrate materials.

The first method described by Matsumoto et al. was the hot-filament method [20], also used by Bichler et al. at TU Wien [25]. Microwave activation was introduced by Kamo et al. shortly after (Fig. 5b) [23]. Several other methods followed, e.g. plasma jets, glow discharges and the acetylene torch. Some schematic drawings are shown in Fig. 6.

The hot-filament method (Fig. 6a) works by thermal decomposition of $\mathrm{H}_{2}$ to obtain at.H, and allows for an easy design and up-scaling of reactors [47, 48]. For filament materials, W or Ta can be used, allowing filament temperatures up to $2500{ }^{\circ} \mathrm{C}$ [49-51]. Inhomogeneous diamond depositions, caused by deviation of substrate temperature and at.H concentrations, can be prevented by arranging several filaments in optimal positions (Fig. 7a) [48]. An advantage of the hot-filament method is that the substrate surface temperature can easily be regulated by additional heating, and no active substrate cooling is necessary. However diamond deposition rates are relatively low (about $1 \mu \mathrm{m} / \mathrm{h}$ ) compared with other methods. As a result of impurities in the diamonds caused by the filament materials, this method is primarily used for diamond coatings on wear parts [52, 53]. Several companies sell hot-filament equipment [54-56].

The acetylene torch (Fig. 6b) also uses high temperatures to generate at.H and is very simple. However, as a result of the small size of the flame and problems with acetylene purity, this method has not gained high importance $[57,58]$.

Microwave plasma diamond deposition (Fig. 6c) with "ball"-shaped plasma is convenient to handle and highly pure diamond can be deposited. Enlarging the deposition areas is difficult, and as a result of the ball-shaped plasma, the diamond quality is inhomogeneous between centre and border of the discharge (Fig. 7b) [43, 44, 59]. An advantage of this method is that microwave power can easily be increased resulting in higher diamond growth rates (greater than $10 \mu \mathrm{m} / \mathrm{h}$ ). The possibility to deposit diamond with high purity is the main advantage of this method [60]. Today, several companies sell microwave equipment for diamond deposition [61, 62].

Balzers (now Oerlikon) introduced a high density/low voltage arc discharge reactor as an industrial process for coating tool materials $[63,64]$. This method produces high concentrations of at.H and therefore allows the coating of a large number of inserts under quite controlled conditions [65].

DC- and arc-plasma jets permit high speed diamond growth on relatively large surfaces, comparable with microwave and hot-filament methods. As the substrates are typically located near the arc, controlled cooling is needed to regulate the substrate surface temperature, which can be a serious problem for mass production applications [66-69].

The DC-glow discharge method (Fig. 6c) allows far higher diamond growth rates, but there are some problems like scale-up, substrate geometry and reproducibility [70-72].

The advantages and disadvantages of the primary processes for hydrogen activation are summarized in the Table 1 [73].

\section{Process parameters and substrate interactions for diamond growth}

As already described, the diamond quality is largely influenced by the ratio of at.H to carbon as well as the substrate surface temperature. Furthermore, there is a large overlap of influences on diamond growth caused by other process parameters such as doping elements and substrate materials. These aspects will be presented separately.

\section{Diamond deposition parameters}

The main parameter which has to be optimized to grow diamond is the correct gas phase composition in terms of the $\mathrm{C} / \mathrm{H} / \mathrm{O}$ ratio compared to the at.H produced [74] (Fig. 8).

Diamond nucleation and growth are the key parameters for diamond deposition, and there are always interactions between the diamond layer, the substrate, and the gas phase. 

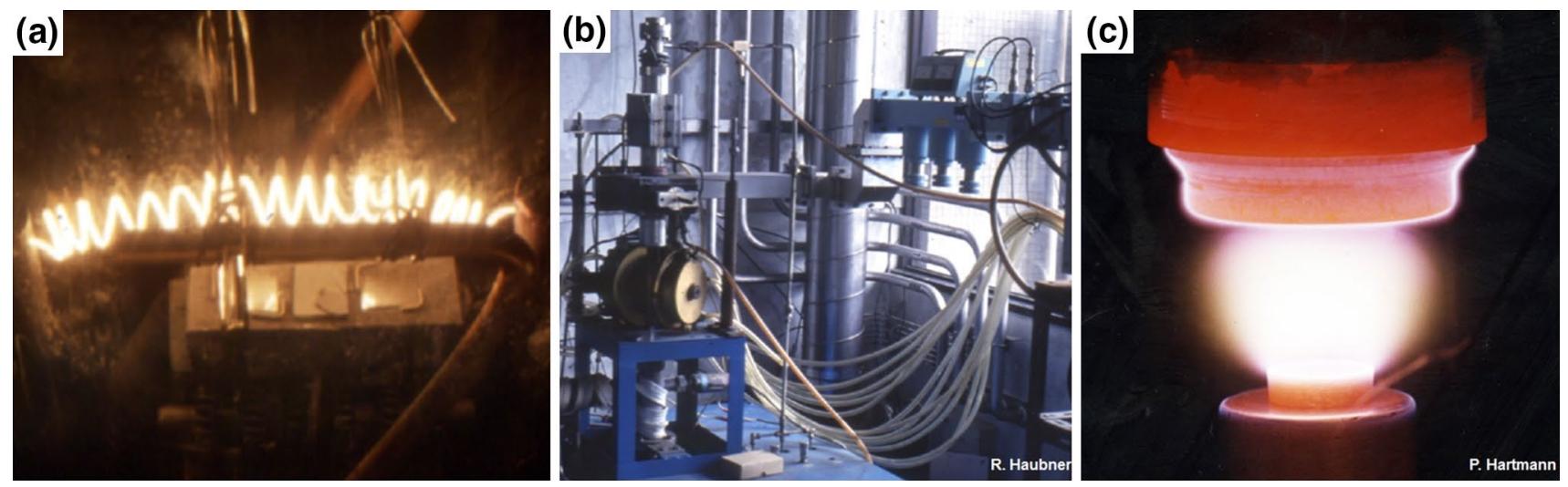

Fig. 5 Examples for diamond deposition methods: a hot-filament equipment at TU Wien, b microwave equipment, first prototype at NIRIM, Tsukuba, Japan, c CD glow-discharge at TU Wien

(a)

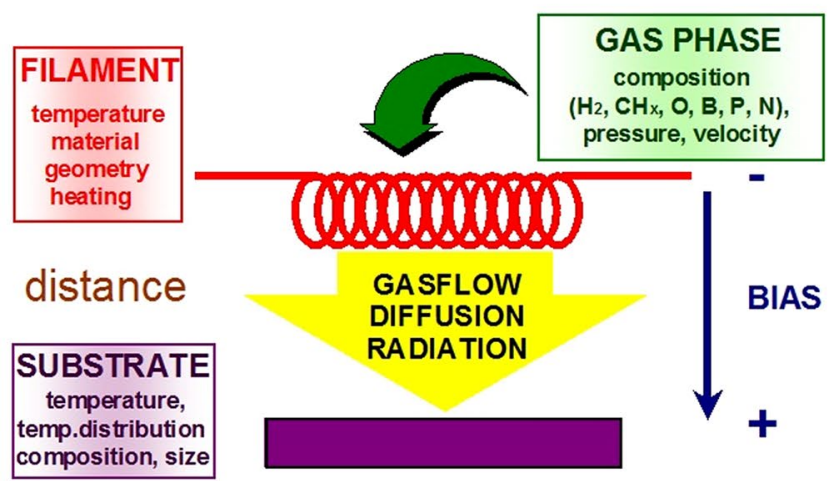

(c)

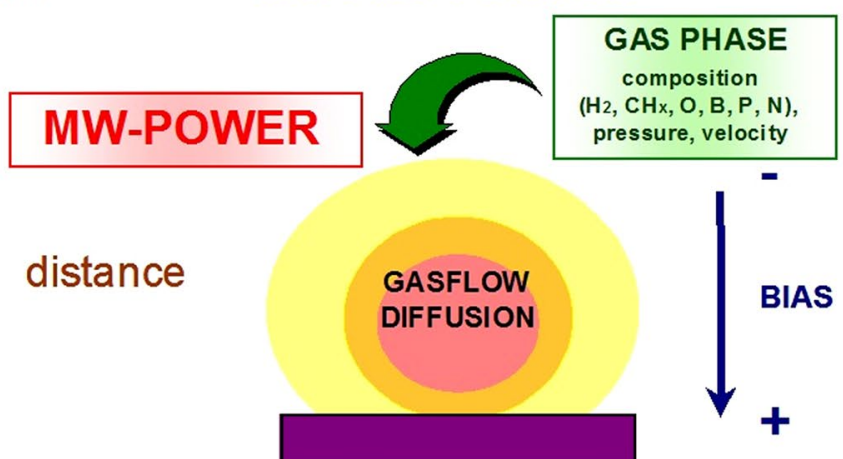

(b)

combustion flame-method

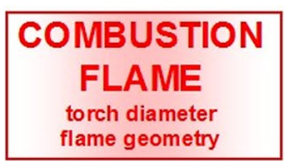

distance

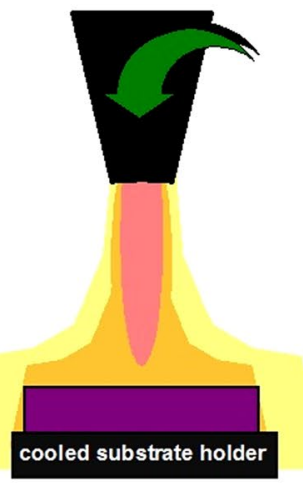

(d)

\section{DC-glow discharge-method}
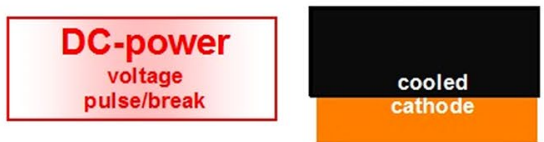

distance

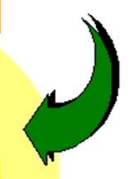

Fig. 6 Schemata of diamond deposition methods: a hot-filament, $\mathbf{b}$ combustion flame, $\mathbf{c}$ microwave, $\mathbf{d}$ DC-glow discharge

The diamond layer formation can be subdivided into three steps: (1) diamond nucleation, (2) growth of individual diamond aggregates which grow together and (3) diamond layer growth (Fig. 9) [27, 75].

If the growth conditions for diamond growth are fulfilled, the final diamond quality is linked to the amount of at.H and the diamond growth rate. High-quality diamond with low defect density requires low diamond nucleation rates and low growth rates. By increasing the growth rate, the defect density in the diamond crystals increases [40]. The defects are mainly micro twins which are preferably formed in (111) growth sectors. If the defect density becomes too high, the diamond surface is not faceted anymore and is then called ballas diamond [76] (Fig. 4). 
(a)

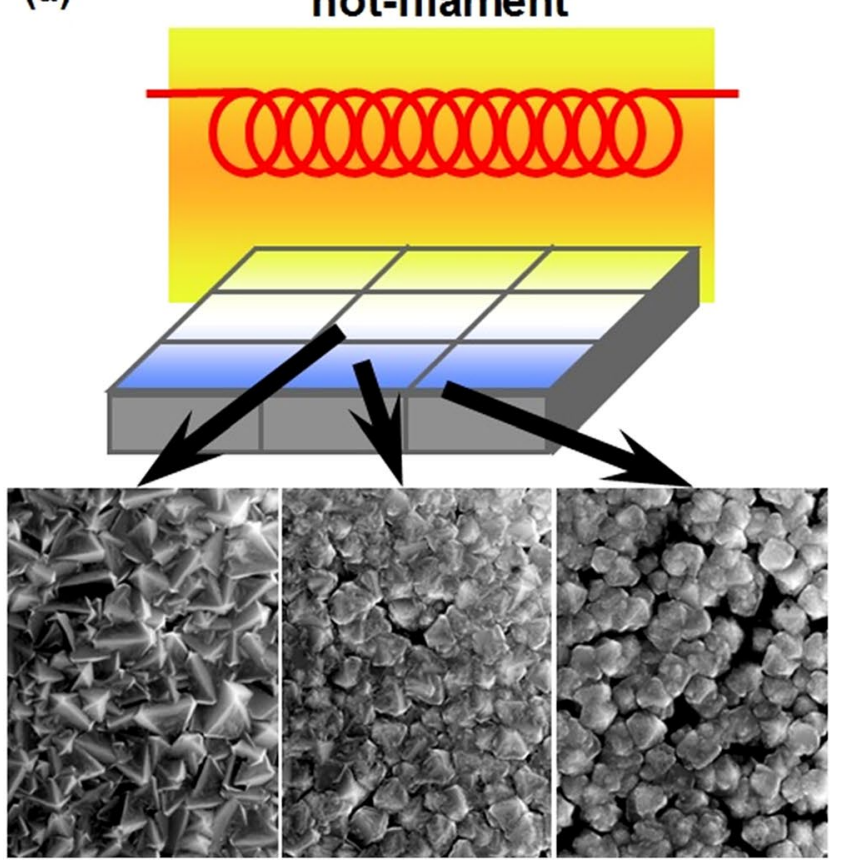

(b)

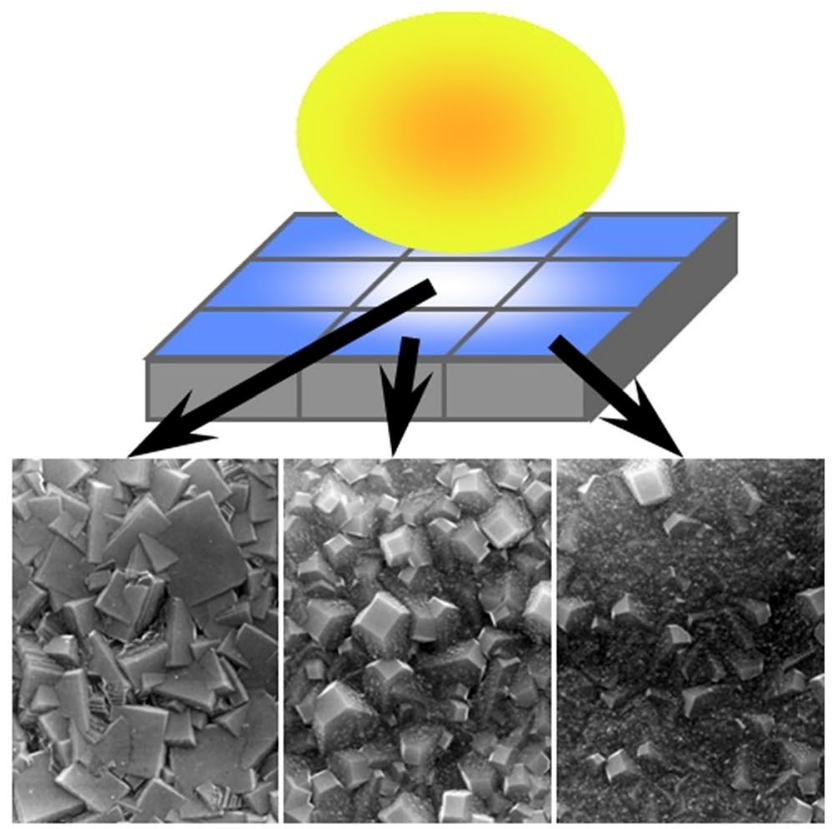

Fig. 7 Geometrical arrangement substrate/plasma and corresponding diamond morphologies: a hot-filament, b microwave plasma

Table 1 Advantages and disadvantages of low-pressure diamond synthesis methods (modified from [73])

\begin{tabular}{lll}
\hline Method & Advantages & Disadvantages \\
\hline Hot-filament & Low equipment costs & Contamination by the filament material \\
& Easy up-scaling & Low growth rates (about $1 \mu \mathrm{m} / \mathrm{h}$ ) \\
Microwave & High diamond quality & "Ball"-shaped plasmas \\
plasma & Easy temperature regulation & Non-uniform thickness \\
& & Difficult for 3D substrates \\
Plasma jets & High growth rates & Forced substrate cooling \\
Glow discharge & High growth rates & Substrate temperature control \\
& & Small deposition areas; planar substrates
\end{tabular}

Different diamond facets can be grown by changing the growth conditions, resulting in different layer morphologies [77]. The layer morphology is additionally influenced by texture formation during layer growth [78] (Fig. 10).

By reducing the amount of at.H compared to $\mathrm{C}$, diamond nucleation is increased and fine-grained diamond coatings are formed. In the case of extreme changes in process parameters, nanocrystalline diamond (NCD) [79, 80] and ultrananocrystalline diamond (UNCD) [81, 82] films are formed. In these coatings the diamond crystals are in the nanometre range and are surrounded by amorphous carbon-containing grain boundaries. As a result of the high number of grain boundaries, the content of the diamond phase is reduced and it is hard to distinguish between diamond (crystalline) and amorphous carbon [83]. As a result of the higher amount of $s p^{2}$ carbon and increased etching by at.H, the layer growth rates are low.
Finally, all process parameters interact and lead to different diamond coatings. An example for the interactions of temperature and gas pressure on diamond growth is shown in Fig. 11 [84]. The gas pressure should be low enough to form high amounts of at.H but also high enough to achieve reasonable diamond growth rates $[31,46]$. The substrate surface temperature should be below $1000{ }^{\circ} \mathrm{C}$ to prevent a transformation of already grown diamond into graphite. However, below $600{ }^{\circ} \mathrm{C}$, the diamond deposition becomes extremely slow [85].

Following the general concept of Bachmann [74], oxygen has no negative influence on diamond growth. This was confirmed by the use of acetone as precursor [86] (Fig. 12) and $\mathrm{CO}$ addition to the gas source [87]. 


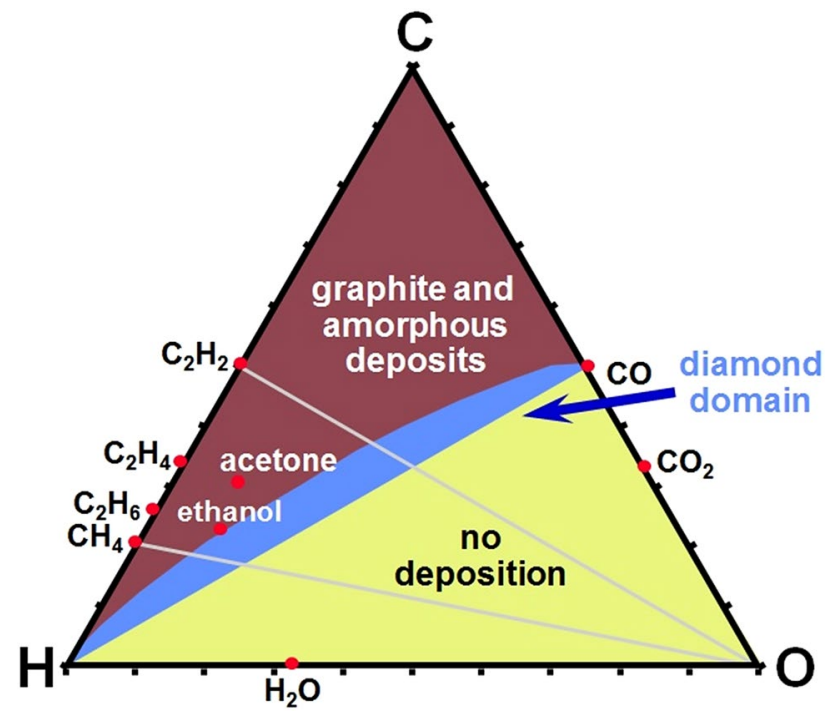

Fig. $8 \mathrm{C} / \mathrm{H} / \mathrm{O}$ mixing diagram visualizing the region of diamond growth if enough at.H is present (modified from [74])

\section{Impurities and diamond doping}

A challenge in this research area is the production of p-type and n-type semiconducting diamond. In the past, boron [88-90], nitrogen [78, 91-93], phosphorus [94-96], lithium [97, 98] and also sulfur [99-101] additions to the diamond deposition process were investigated (Fig. 13a).

Boron addition during low-pressure diamond deposition has been used for quite a long time [90, 102, 103], as small boron concentrations increase diamond growth rates and improve crystallinity. Later on boron-doped diamond became interesting for semiconducting technology (p-type) [104] and for electrodes in electrochemistry [105]. The deposition methods usually attain gas activation by microwave plasma or a hot filament. In case of the hot-filament method, the reactions of the metallic filament materials with boron (formation of borides) have to be taken into account [106].

For boron concentrations in the gas phase below $500 \mathrm{ppm} \mathrm{B/C}$, independent of the boron source and the deposition method used, an improved diamond quality is commonly found [107, 108]. Slightly increased diamond crystal sizes are observed and the crystal habitus becomes better pronounced.

B concentrations between 1000 and $5000 \mathrm{ppm} \mathrm{B/C}$ decrease the diamond growth rates to values comparable to undoped layers. Diamond morphology remains fairly
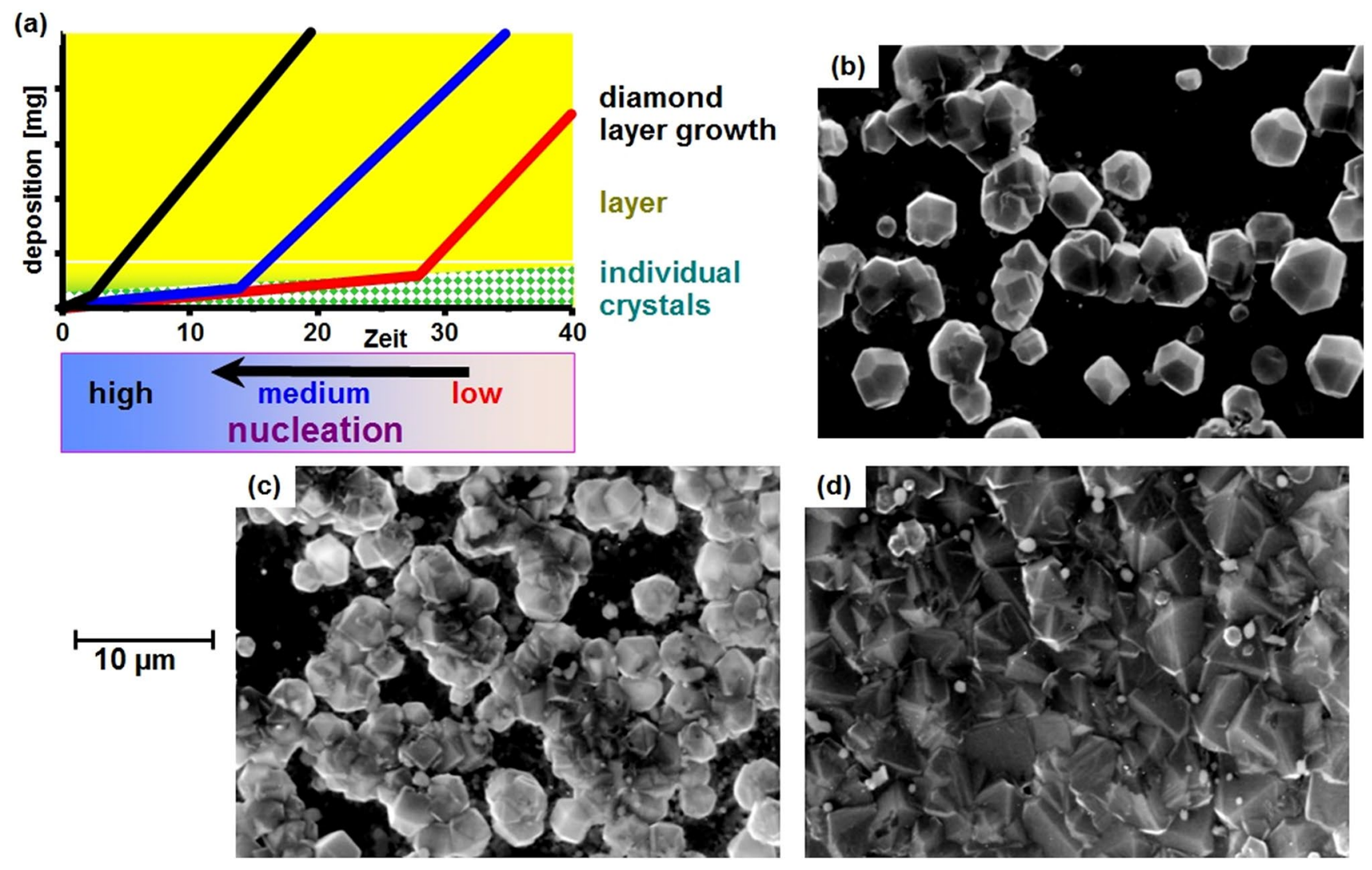

Fig. 9 Diamond layer formation is influenced by the diamond nucleation rate. a Diagram illustrating the influence of diamond nucleation on the diamond deposition rate, $\mathbf{b}$ individual diamond crystals, $\mathbf{c}$ coalescence of diamond crystals, $\mathbf{d}$ diamond layer 


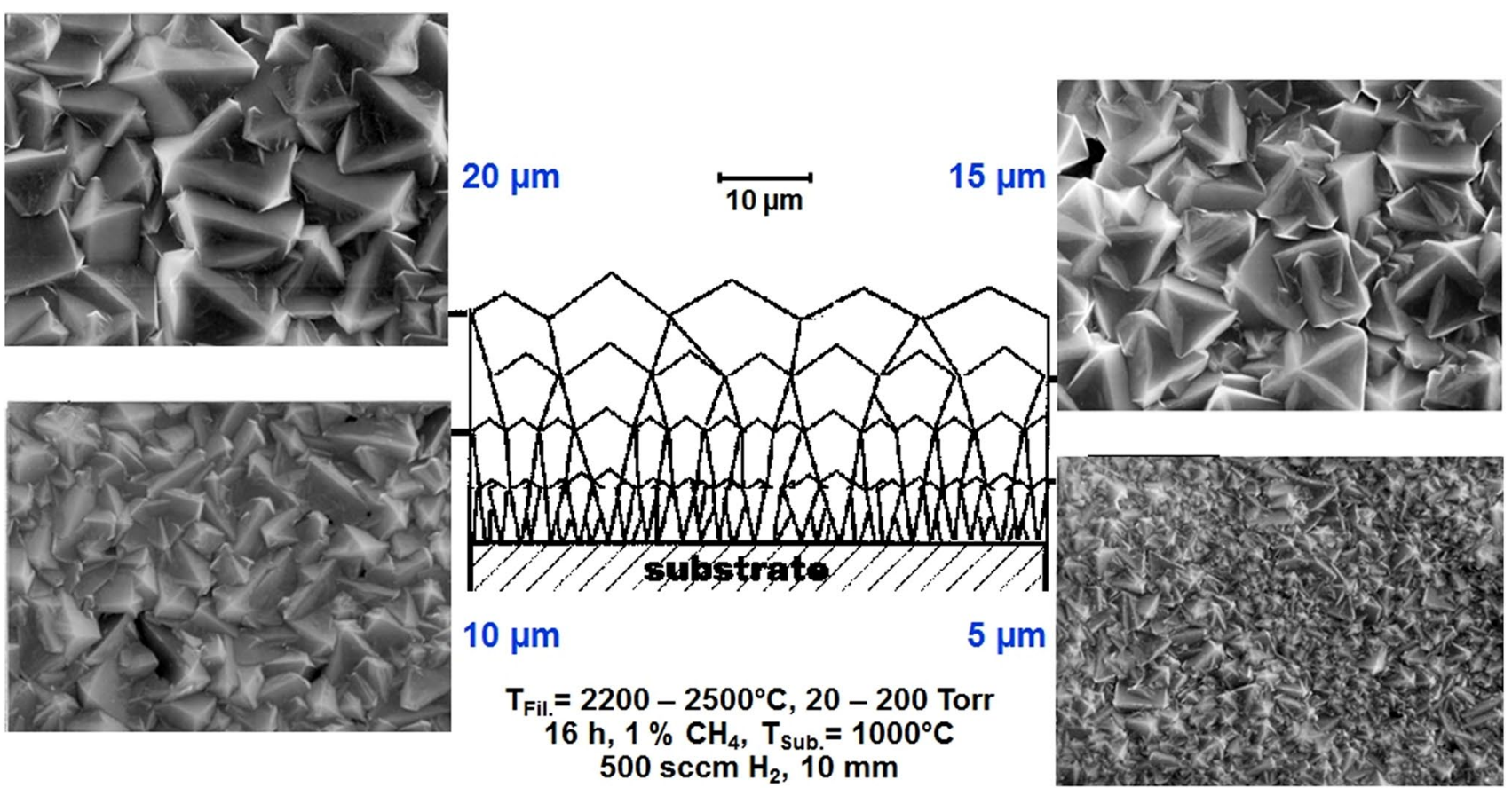

Fig. 10 Correlation between visible diamond crystal size and layer thickness

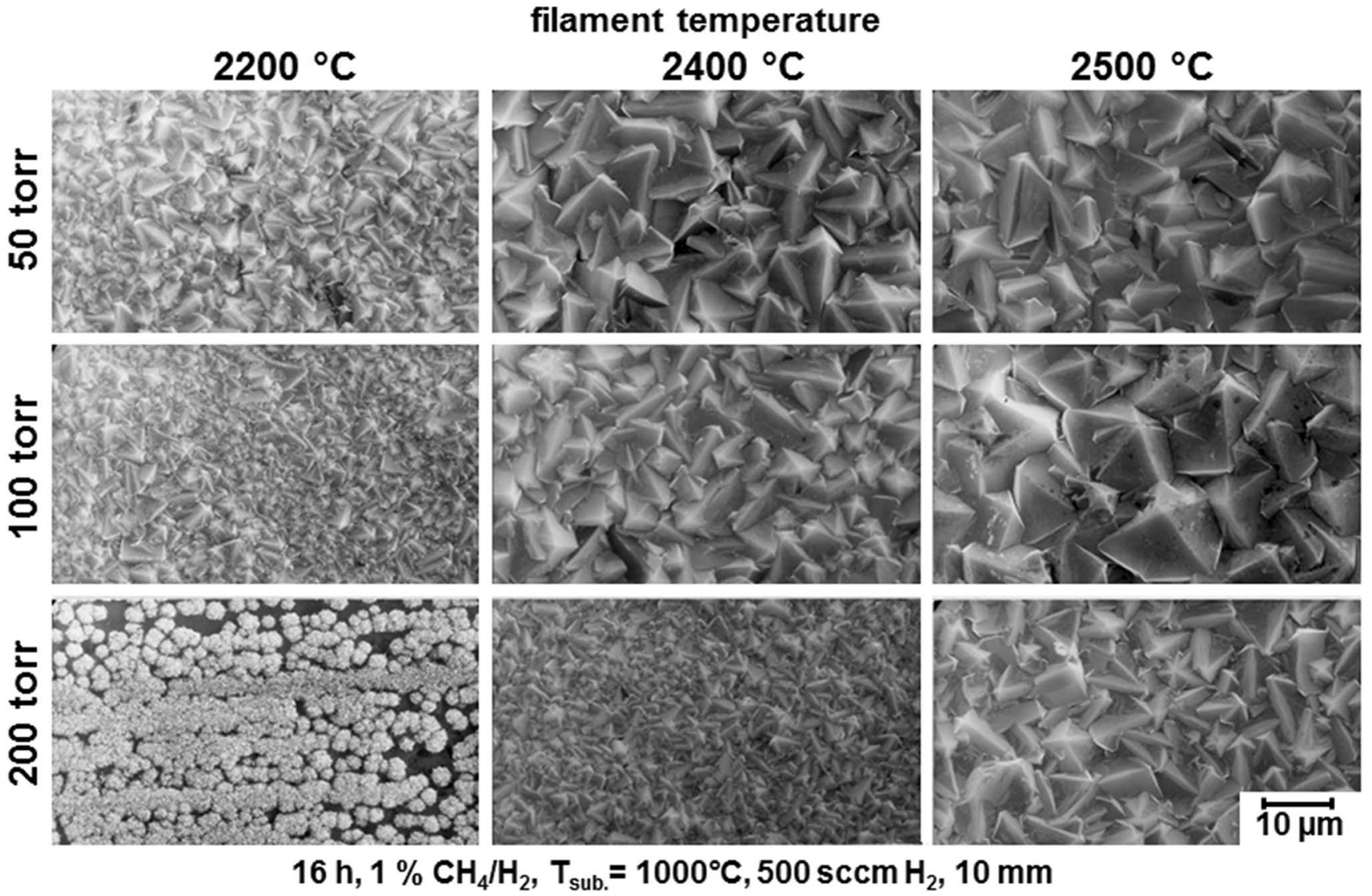

Fig. 11 Example for the influence of the process parameters temperature and pressure on the diamond deposition with otherwise constant deposition parameters (modified from [57, 84]) 


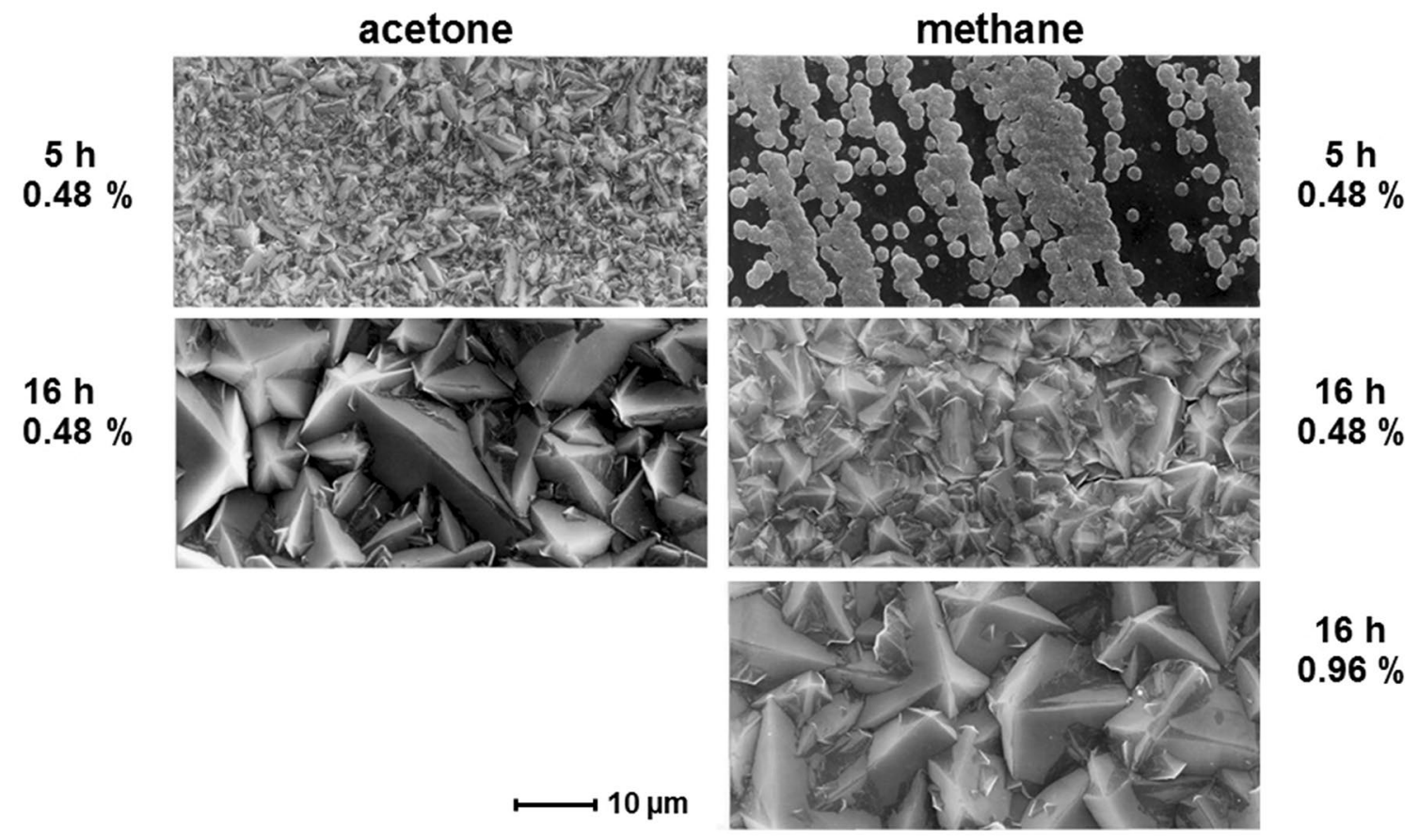

Fig. 12 Comparison of acetone and methane as precursors for diamond deposition (modified from [86])

constant with steadily decreasing crystal size. Optical microscopy and scanning electron microscopy (SEM) [88] of polished diamond samples visualise the inhomogenities in boron distribution. Boron is incorporated up to 3 at. \% in the (111) and less than 0.3 at.\% in the (100) grown sectors (Fig. 14) [109, 110].

The n-type doping of diamond received great interest, and addition of traces of $\mathrm{P}, \mathrm{N}, \mathrm{S}$ and $\mathrm{Li}$ was investigated. Any addition of impurities to the diamond deposition process influences diamond growth rate, morphology, as well as quality and properties of the deposited diamond [111].

Considering only steric and energetic factors, an introduction of phosphorus into the diamond lattice seems unlikely since the covalent radius of phosphorus is larger than that of carbon [112]. Even small amounts of phosphorus in the gas phase inhibit well-faceted diamond growth [94]. Nevertheless, some reports on the formation of n-type CVD diamond films using phosphorus-containing doping sources are found in the literature [95, 96, 113].

The influence of nitrogen was studied early, due to leakages or residues in the reaction gases (commonly found in $\mathrm{H}_{2}$ and $\mathrm{CH}_{4}$ ). Small contaminations of nitrogen influence the diamond growth and crystal orientation drastically [93, $114,115]$. The outstanding electrical $[91,116]$ and thermal [117] properties of diamond layers are changed by small and medium nitrogen additions.
Research of sulfur-doped diamond [118, 119] was driven by the hunt for an n-type semiconducting diamond $[120,121]$, but in the end the results were not promising.

An interesting result was obtained when $\mathrm{B}$ and $\mathrm{N}$ were added simultaneously (Fig. 15) [122]. In this case diamond and graphite were deposited side by side, which contradicts the principle of low-pressure diamond growth that at.H etches away all the $s p^{2}$ carbon.

\section{Influence of substrate materials on diamond growth}

The interactions between substrates and diamond deposition are rather complex because diamond nucleation and growth can be influenced (Fig. 16).

Most important are reactions between the substrate and the carbon and atomic hydrogen in the gas phase. A subdivision into inert substrates, substrates forming carbides or showing carbon solubility, and substrates being attacked by atomic hydrogen can be made.

- Inert substrates: diamond [123], c-BN [124], SiAlON $[27,44], \mathrm{Cu}, \mathrm{Au}[125]$

- Carbide-forming substrates: refractory metals (e.g. Mo, W, Ta [126-128]), but also Si [129, 130]

- Metals with carbon solubility: ferrous metals ( $\mathrm{Fe}, \mathrm{Co}, \mathrm{Ni}$ [131, 132], $\mathrm{Ni}_{3} \mathrm{Ge}$ [133]) and precious metals (e.g. Pt, Pd $[125,134])$ 


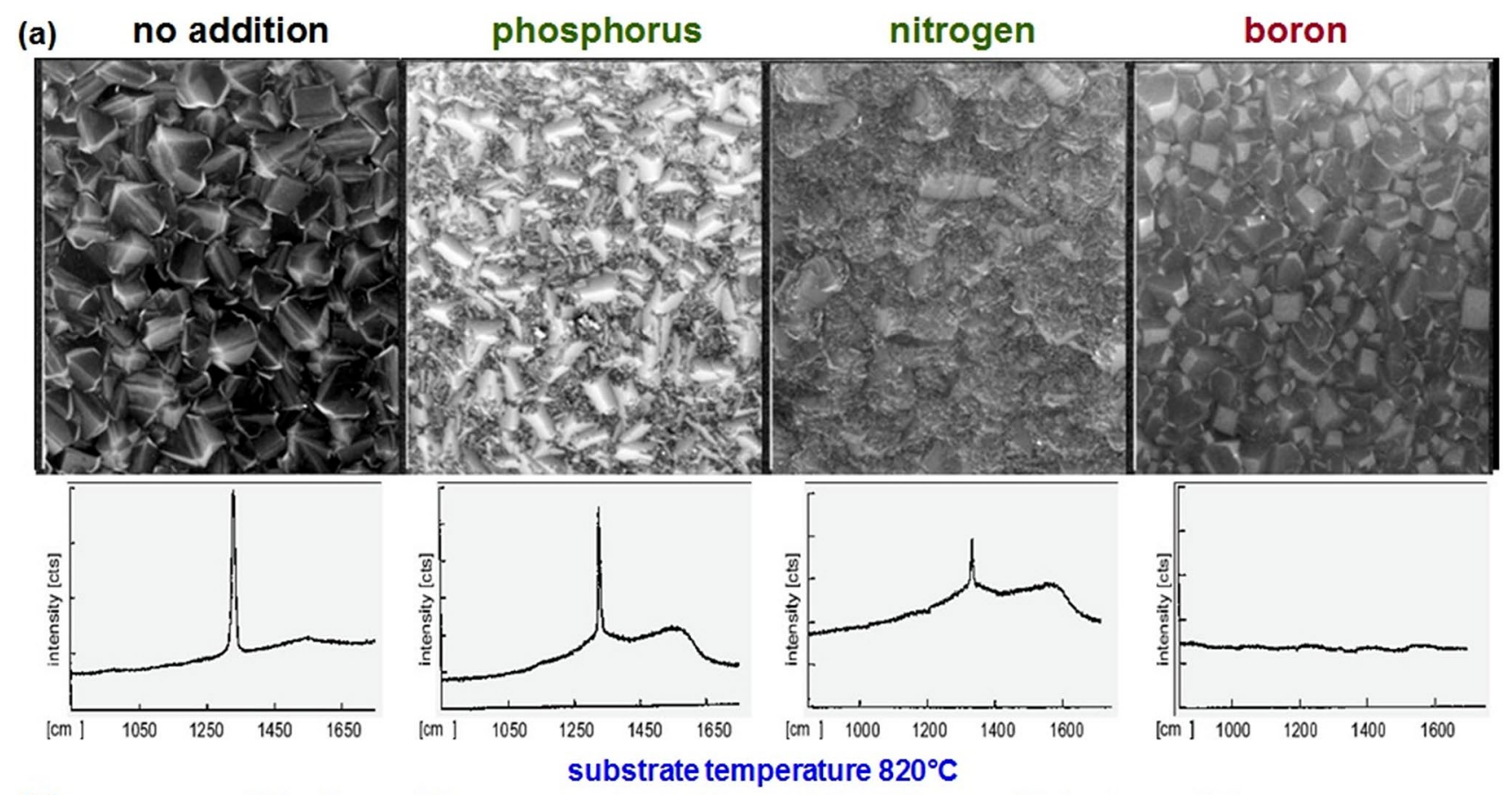

(b)
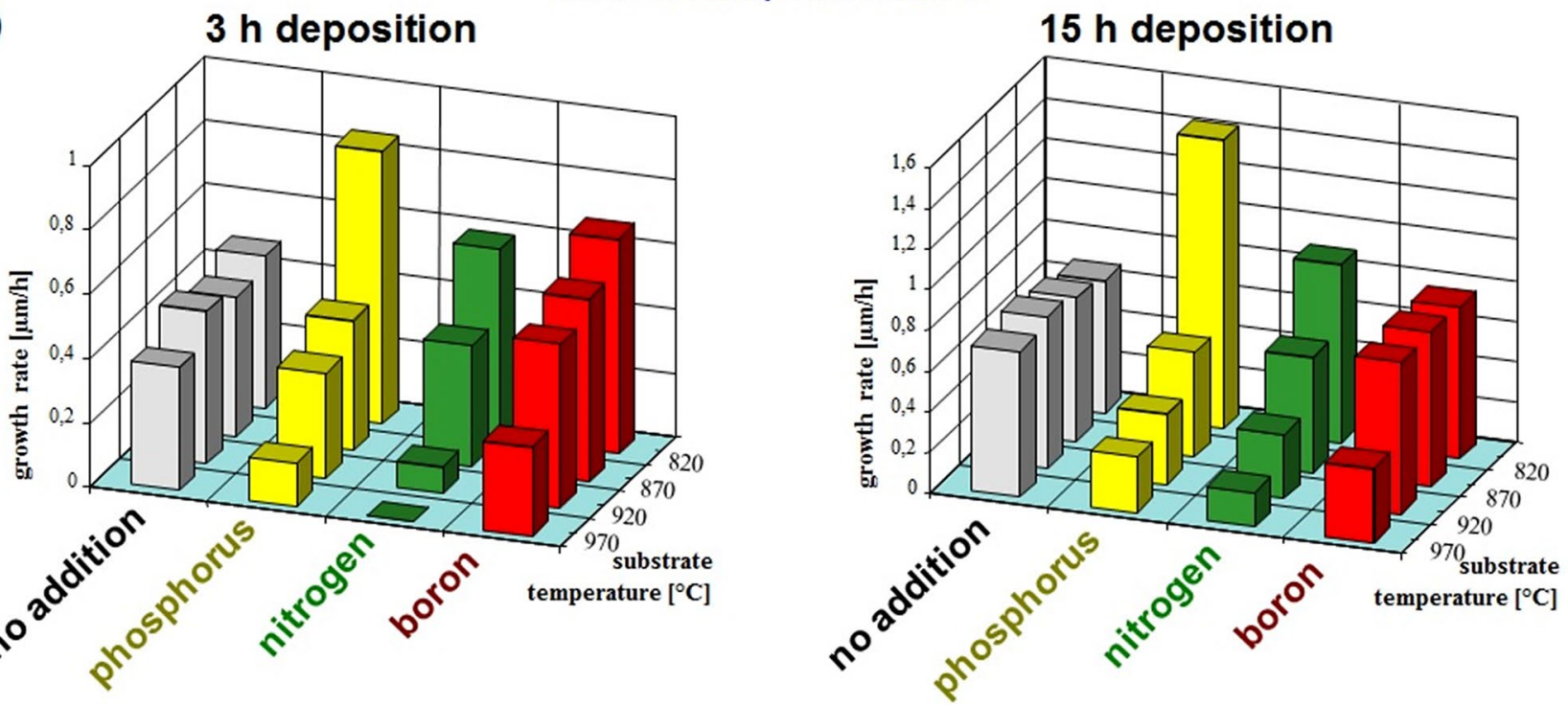

$2500^{\circ} \mathrm{C}, 20 \mathrm{mbar}, 500 \mathrm{sccm} \mathrm{H} \mathrm{H}_{2}, 1 \% \mathrm{CH}_{4}, \mathrm{PH}_{3} / \mathrm{CH}_{4}=0.00066, \mathrm{~N}_{2} / \mathrm{CH}_{4}=5, \mathrm{~B}\left(\mathrm{C}_{2} \mathrm{H}_{5}\right)_{3} / \mathrm{CH}_{4}=0.0035$

Fig. 13 Influence of $\mathrm{P}, \mathrm{N}$ and $\mathrm{B}$ compounds in the gas phase during diamond deposition: a typically developed diamond morphology for the individual additives and associated Raman spectra, $\mathbf{b}$ influence of the substrate temperature on the diamond growth rate (modified from [111])

- Samples attacked by at.H: h-BN, $\mathrm{Al}_{2} \mathrm{O}_{3}$ [135], graphite $[136,137]$

Some examples for diamond growth on various substrates are shown in Fig. 17.

One field of interest was the diamond deposition on silicon because carbide formation is negligible and there is the possibility for epitaxial diamond nucleation to grow large area single crystalline diamonds [138, 139]. Epitaxy on $\mathrm{Si}$ is not perfect and many investigations with epitaxial intermediate layers were necessary to reach the goal. In 2017 Schreck [140] reported a single crystalline diamond plate with a diameter of about $92 \mathrm{~mm}$.

Another important substrate material is hardmetal (WC-Co) [141], which is used for tool applications. When using WC-Co, problems are mainly caused by the Co binder [142], as the Co interacts during the diamond deposition in different ways [143, 144]. Cobalt catalyses the deposition of $s p^{2}$-non-diamond carbon, and it also has a relative high vapour pressure influencing the gas phase above the 


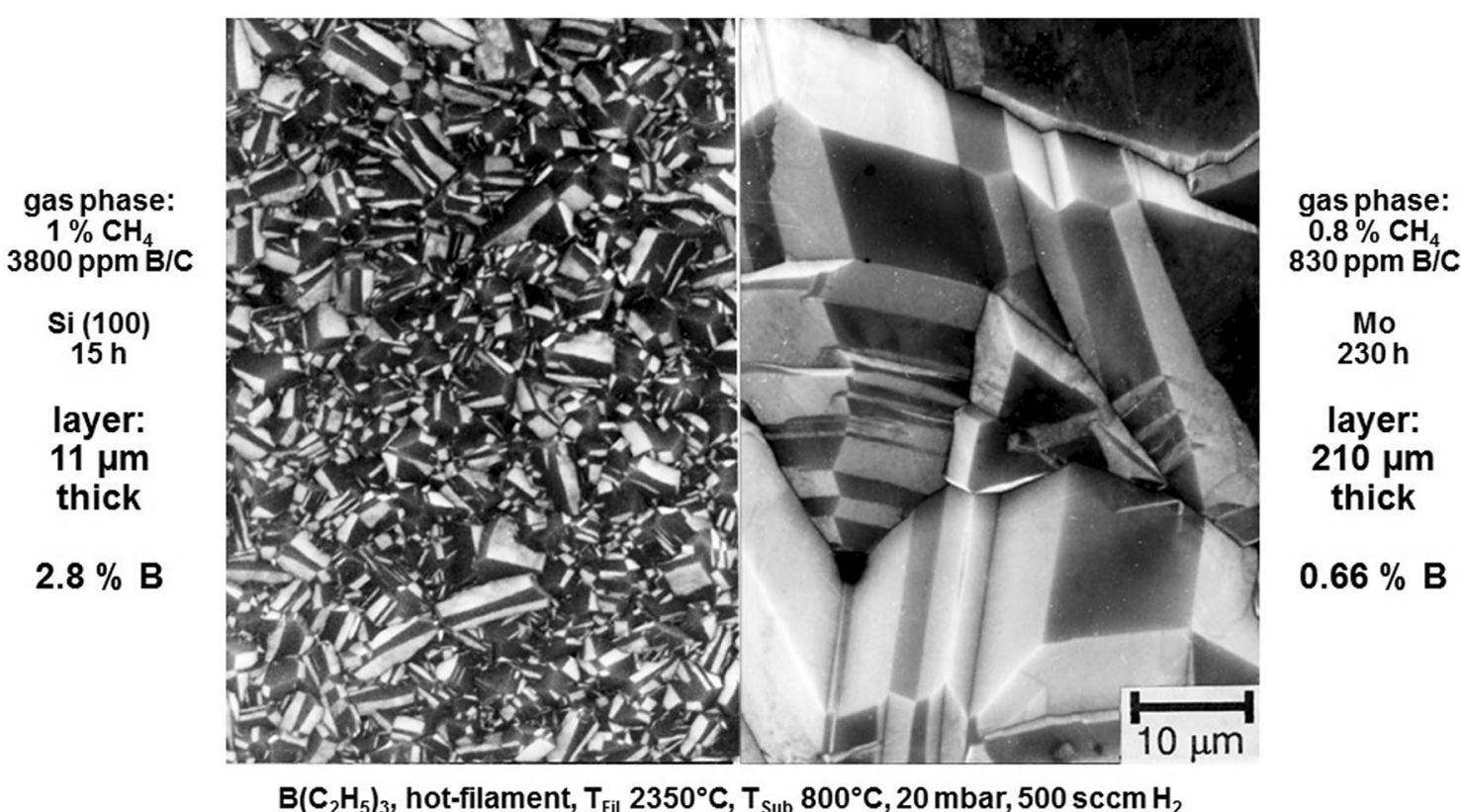

Fig. 14 Example of the inhomogeneous incorporation of boron in different crystal faces. In SEM images, crystal surfaces containing boron appear darker because the electrons from SEM are diverted and there is no charging (modified from [88, 109])

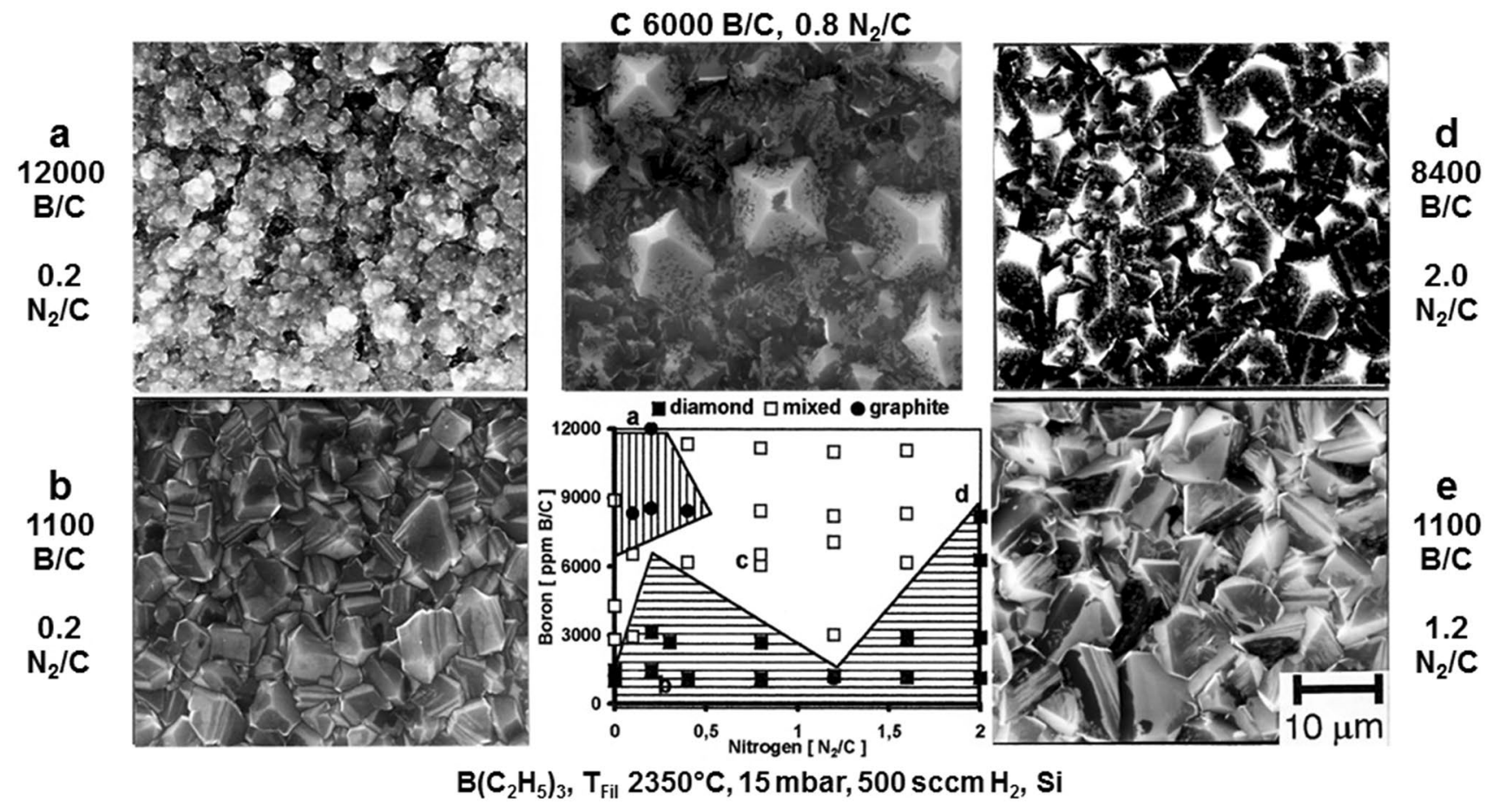

Fig. 15 Simultaneous addition of boron and nitrogen during diamond deposition, resulting in mixtures of diamond and graphite (modified from [122])

substrate [145]. The $s p^{2}$-carbon (graphitic) has a negative influence on the adhesion of the diamond coatings.
The effects of Co during diamond deposition can be described as follows (Fig. 18): 
Fig. 16 Illustration of the influence of substrate properties on the diamond nucleation

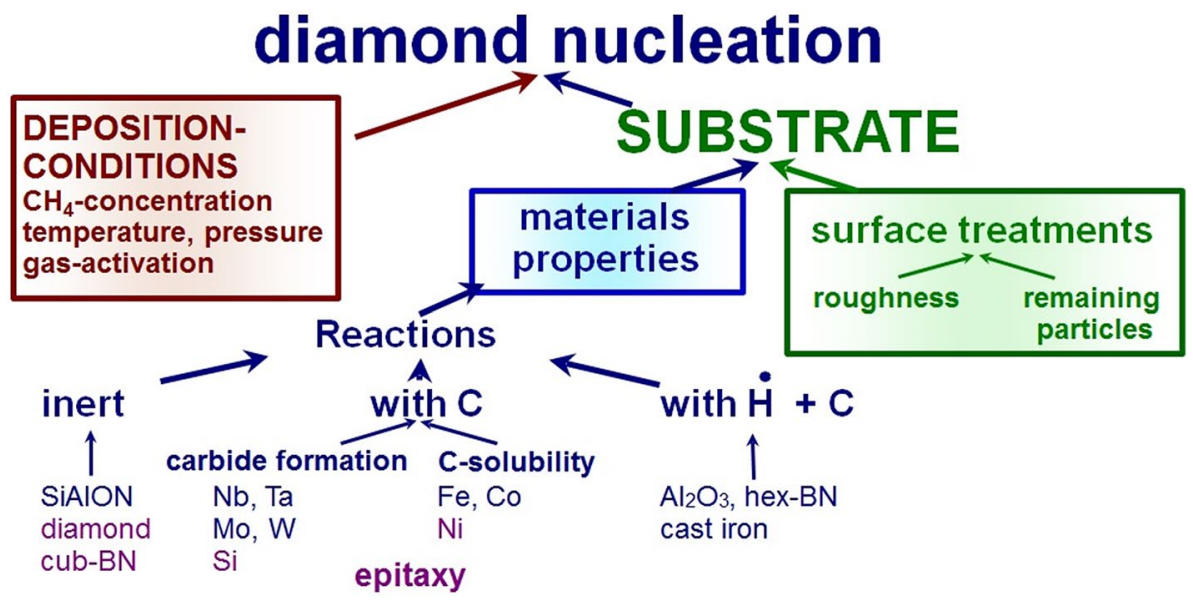

- Co migration takes place at the substrate surface, and Co droplets are formed [143, 146, 147].

- During the deposition process, carbon and parts of already deposited diamond diffuse into the hardmetal, because the Co binder phase has solubility for carbon [148]. For the diamond coating to adhere well to hardmetal tools, it is necessary to saturate the cobalt binder with carbon before the diamond is deposited [148].

- With increasing contents of Co and carbides like TiC in the hardmetal alloy, the thermal expansion coefficient increases, and as a result of the lower thermal expansion coefficient of diamond, compressive stress occurs in the diamond coating during cooling from deposition temperature. This is one reason for the reduced coating adhesion on the substrate [135].

To overcome the problems concerning Co it is necessary to reduce its surface mobility or surface concentration (Fig. 19).

$\Rightarrow$ Etching of Co by various acids.

Selective etching of the Co binder phase with various acids offers a wide range of different pre-treatment methods. The thickness of the etched zone is important because remaining porosity in the hardmetal results in reduced layer adhesion [149, 150].

$\Rightarrow$ Etching of WC and Co.

Etching of WC/Co composites can be achieved by a welltailored two-step etching treatment, where a Murakami solution $\left(\mathrm{K}_{3}\left[\mathrm{Fe}(\mathrm{CN})_{6}\right]\right.$ in $\left.\mathrm{KOH}\right)$ is used to attack the WC first, and in a second step the remaining Co sponge is dissolved by Caro's acid $\left(\mathrm{H}_{2} \mathrm{SO}_{4}\right.$ with $\left.\mathrm{H}_{2} \mathrm{O}_{2}\right)[151,152]$. Diamond nucleation is favoured by the rough, etched surface resulting in a good layer adhesion.

$\Rightarrow$ Thick intermediate layers.

Intermediate layers should cover the substrate and encapsulate the Co. The material selection for such interlayers is difficult, because they must be stable during diamond deposition and diamond nucleation should be fast enough for rapid layer formation. Additionally, the interlayers should have a low thermal expansion coefficient to reduce stress at the interface $[153,154]$. Various CVD and PVD coatings were tested as intermediate layers, but these experiments were not successful because of insufficient diamond nucleation on the intermediate layers and poor diamond adhesion.

$\Rightarrow$ Thin layers formed by surface reactions with Co.

Different methods were used to form stable Co compounds at the hardmetal surface. A simple heat treatment with B or Si was very effective, as can be seen in Fig. 19. SEM pictures show well-faceted diamond, Raman confirmed higher quality of the deposited diamond, and no Co droplets on the coating surface are visible [144].

To find more simple methods for the surface treatments various other procedures were investigated [155-158].

Nowadays variations of Murakami/Caro etching are the most frequently used pre-treatment for hardmetal tools.

Carbon substrates need tricky deposition conditions in order to coat them with diamond, because graphite is attacked by at.H [159, 160]. Carbon substrates can be used for electrode materials owing to their electrical conductivity and better corrosion resistivity compared with metals.

Steel substrates are also of interest for diamond deposition, because high speed steels (HSS) are widely used in tool industry. As a result of the high carbon solubility in iron at the typical diamond deposition temperatures (greater than $750{ }^{\circ} \mathrm{C}$ ), direct deposition on steel is not possible [153, 161, 162]. Additionally, the thermal expansion coefficient of steel is high, causing problems with compressive stress in coatings after cooling down from deposition temperatures. Nevertheless, several PVD coatings were tested as intermediate layers for diamond deposition [161]. These experiments were not successful and no commercial products of diamond-coated steel tools are currently available.

Finally, the chemical properties of the substrate influence the diamond growth as do the surface roughness and 

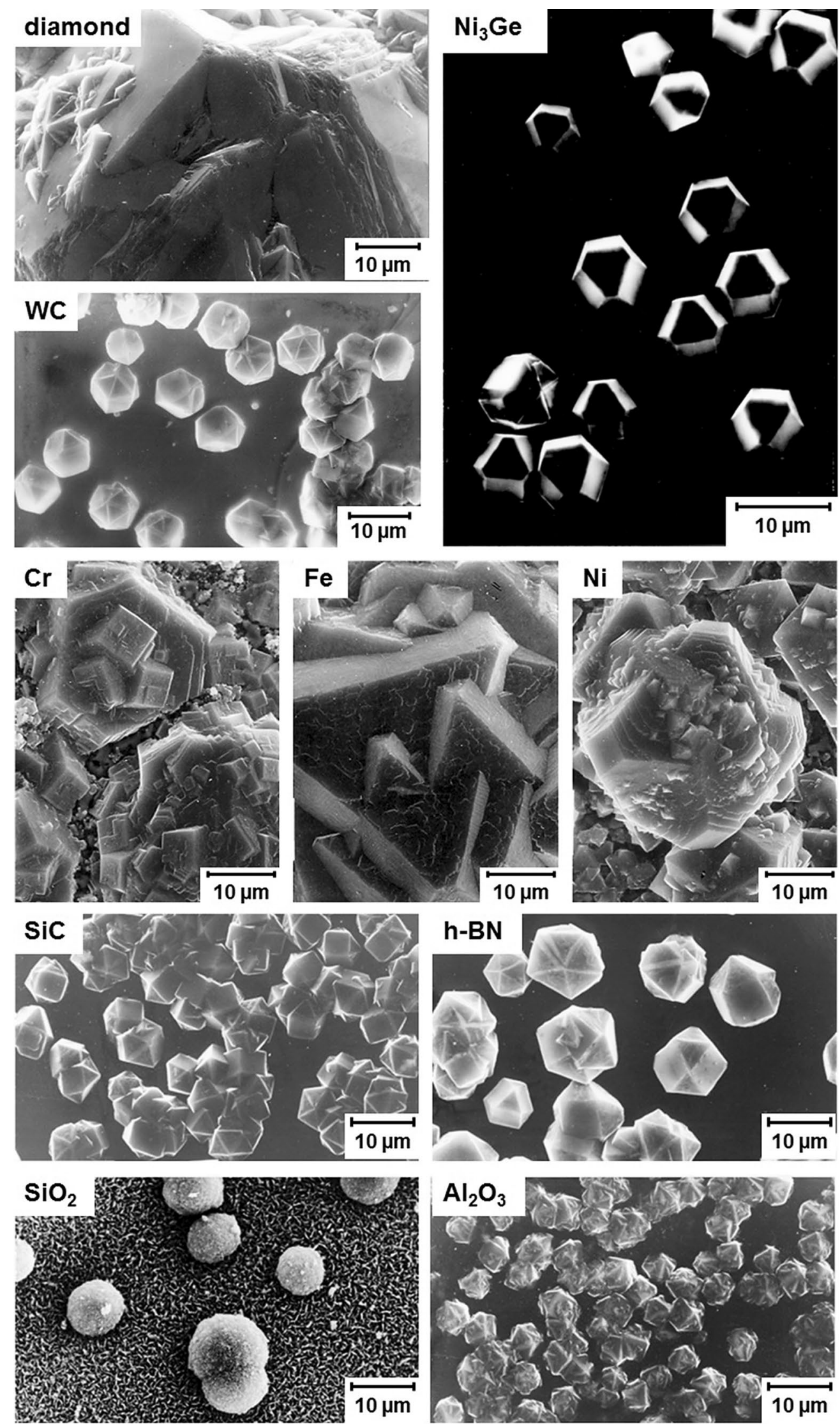

Fig. 17 Diamond deposition on various substrates 

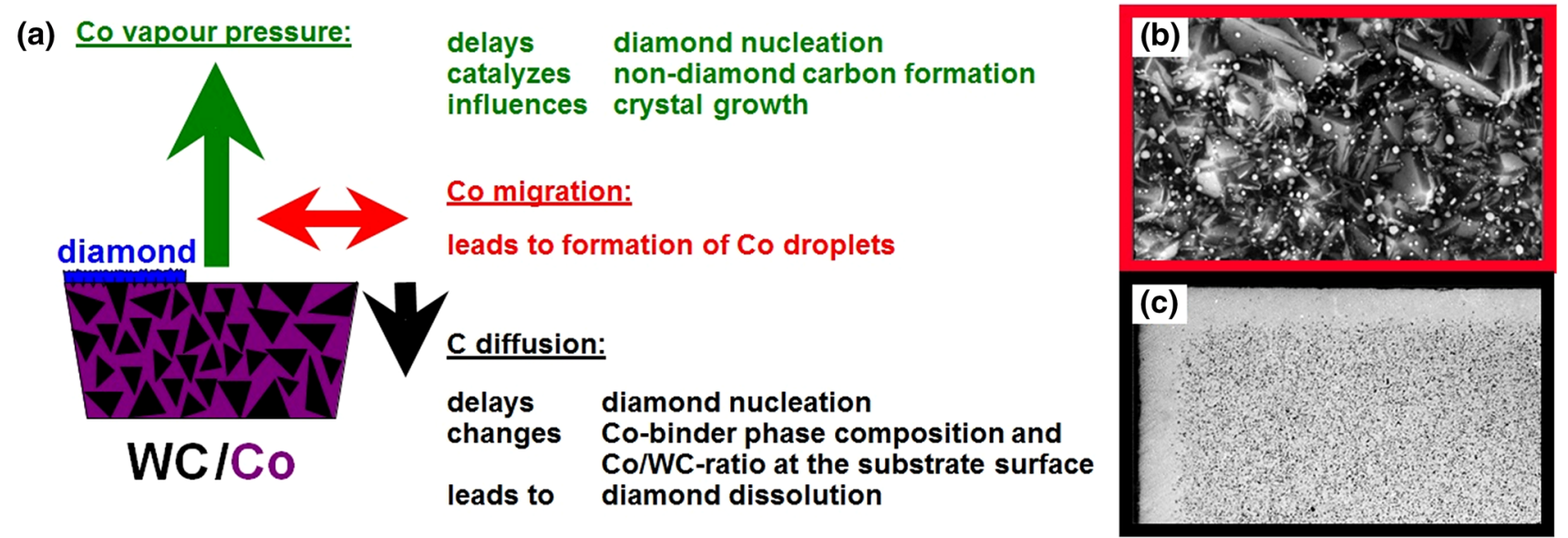

Fig. 18 Interactions of the Co binder phase in the hardmetal during diamond deposition. a Schematic representation (modified from [142]), b Co droplets on the diamond surface (modified from [145]), c diffusion of C into a substoichiometric hardmetal substrate (modified from [145])

(a)

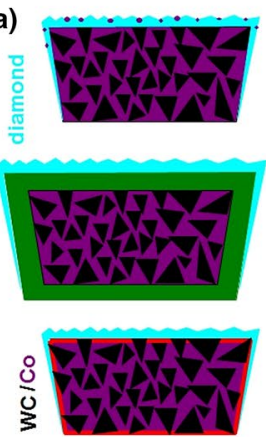

no surface treatment

Co influences:

vapour pressure; migration carbon dissolution into the substrate

intermediate layer

Co influences are pushed back no Co vapour pressure and migration; interactions with the coating materials

\section{stable Co compounds}

smaller Co influences: vapour pressure and migration are reduced; higher diamond nucleation
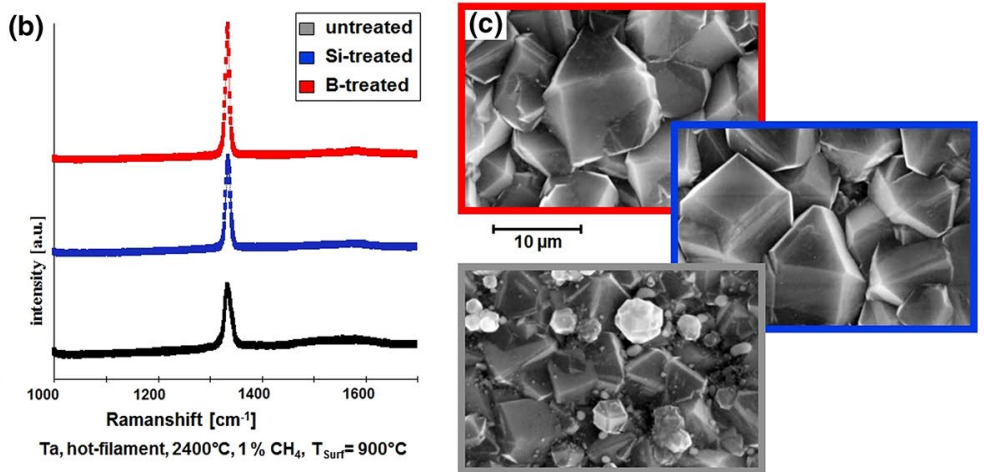

Fig. 19 Hardmetal surface treatments prior to diamond deposition: a comparison of etching, intermediate layer and surface treatment (modified from [142]), b surface treatment with B and Si c diamond morphologies after the surface treatments (modified from [144])

remaining particles from surface preparation (Fig. 20). On a rough surface, there are more active spots allowing the nucleation of diamond. Very often diamond is used for grinding the substrates, but also seeding with nano-diamond is often used. In this case it is not diamond nucleation but diamond growth on the seed crystals. Changes in diamond nucleation rates or seeding results in different diamond growth rates as can be seen in Fig. 9 [45, 127].

\section{Analytical characterisation of diamond}

When CVD diamond research started, Raman measurements were necessary for a clear identification of diamond [26]. The Raman peak at $1332 \mathrm{~cm}^{-1}$ is characteristic for the diamond crystal lattice. The better the crystallinity of the diamond crystal, the higher this peak is. In case of crystal defects or impurities, the peak intensity decreases [40]. Additionally, different types of $s p^{2}$ carbon can be detected.
The availability of new Raman equipment with different laser wavelengths makes the situation more complicated because the wavelength of the laser influences the position and intensity of the different peaks (Fig. 21a, b) [40, 163-165].

CVD diamond coatings have been investigated by almost all available analytical methods [76, 88, 109, 166-170], the discussion and interpretation of which are impossible in this paper.

Only one example for cathodoluminescence is shown in Fig. $21 \mathrm{c}$, and different coloured diamond aggregates can be seen side by side [171]. 


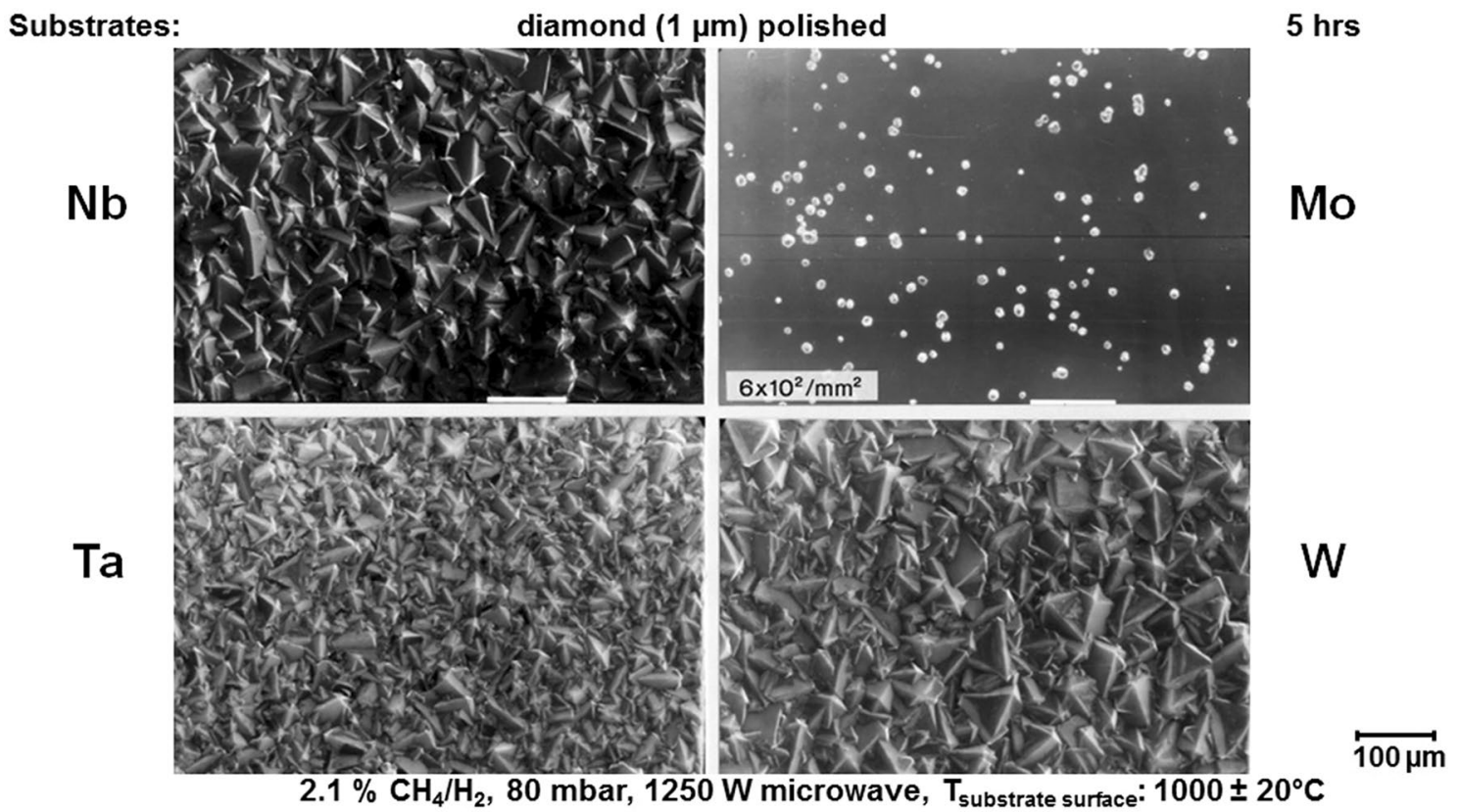

Fig. 20 Influence of the substrate surface and the substrate material on diamond nucleation (modified from [127])

\section{Applications for diamond, focusing on CVD diamond}

The excellent properties of diamond, including its extreme hardness, wear resistance, thermal conductivity and transparency predestine low-pressure diamond to become the ideal material for coatings on wear parts, heat-spreaders, and optical windows. The electrical conductivity of borondoped diamond allows for electrochemical applications Fig. 22.

The dream of diamond-based microelectronics has unfortunately not come true, because of difficulties with p-doping of diamond [172].

Superconductivity $[173,174]$ and quantum dots light sources [175] have also been observed as special properties of diamond.

\section{Diamond coatings for wear parts}

The high hardness and wear resistance qualify diamond coatings for tool applications, which were developed quickly. Diamond-coated hardmetal tools have similar properties to PCD (poly-crystalline diamond sintered at high pressure), but the production costs of CVD diamond are significantly lower $[53,176]$. For CVD diamond applications, two different application paths are possible [177-180]:

(a) Applications for free-standing diamond layers.

Free-standing diamond layers are binder-free (100\% diamond), and their wear resistance can be higher than that of
PCD. Several production steps are necessary from the diamond deposition to the final part. At first, a thick diamond layer is deposited on dummy substrates (e.g. Si, Mo etc.) before the layer is removed from the substrate and laser-cut to the final shape. Finally, the diamond sheets are bonded to the wear parts and finished by grinding.

(b) In situ diamond coatings on tools.

For most wear applications the diamond is deposited directly on the substrate. A very intensively investigated application is the diamond deposition on hardmetal (WC-Co) substrates (Fig. 22a) [177].

A comparison between commercially produced CVD diamond-coated tools and uncoated ones for the processing of various materials has been reported by several companies (e.g. Oerlikon Balzers [65, 181], Boehlerit [182], CemeCon [183]).

In this context, there were also extensive studies on the friction and wear of diamond layers [184, 185].

\section{Diamond coatings with high heat conductivity}

Diamond's highest thermal conductivity (at room temperature) and good electrical insulation make it a desirable packaging material for semiconductors.

High-quality diamond layers are achieved by carefully selecting the diamond deposition parameters. Defects and impurities dramatically decrease the heat conductivity. The processing of heat spreaders requires flat layers with a uniform thickness (Fig. 22b) [92, 186, 187]. 

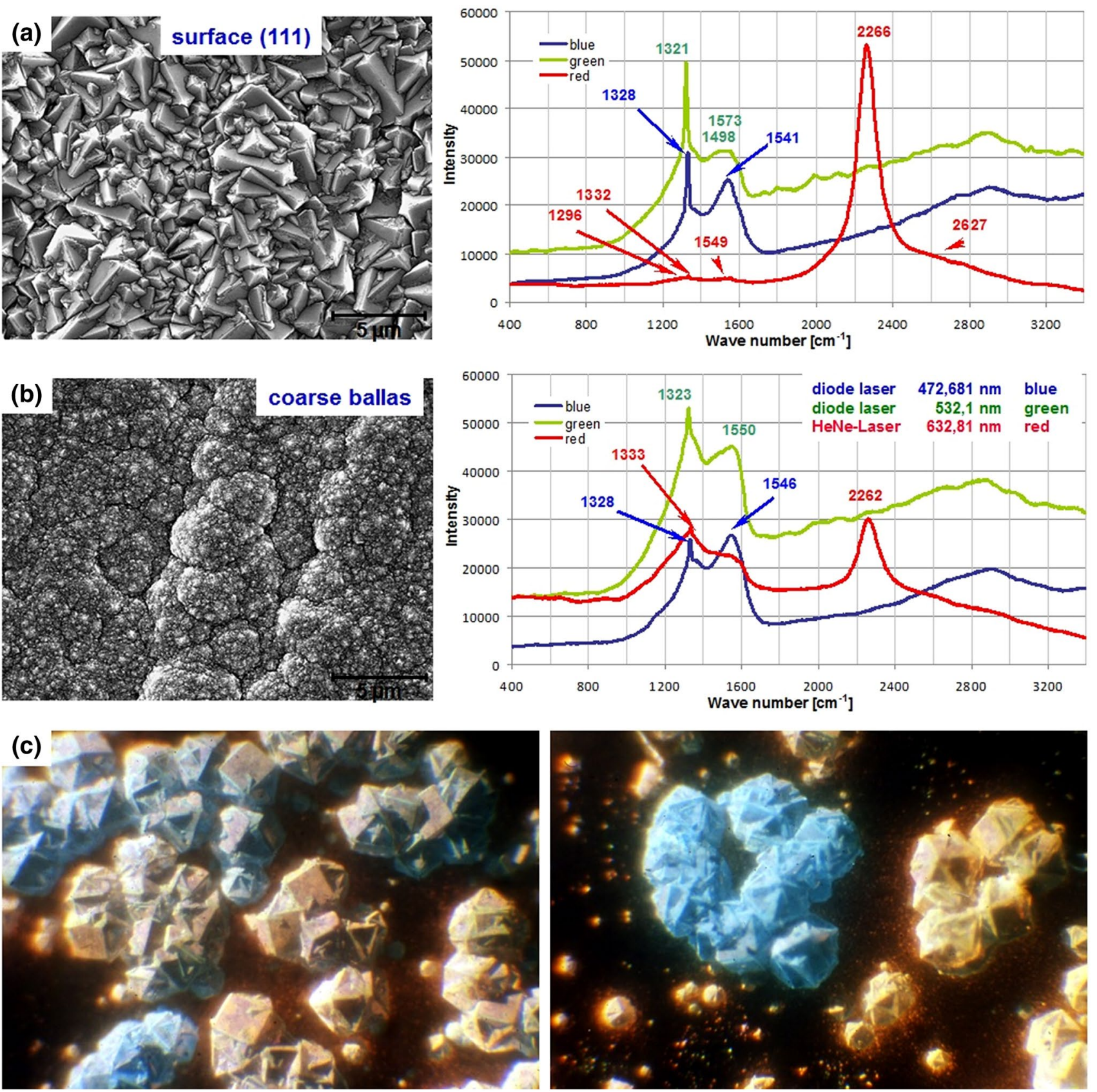

Fig. 21 Characterisation of diamond with Raman at different wavelength (a, b) (modified from [163, 164]), (c) cathodoluminescence (modified from [171])

\section{Diamond coatings for electrochemical applications}

Boron-doped diamond exhibits electrical conductivity and a large electrochemical window. A high overpotential prohibits the decomposition of water, and because of this other chemical reactions are possible [188-190]. A typical application is in industrial wastewater treatment [105]. It was shown that organic carbon can be completely converted to carbon dioxide without the formation of byproducts (Fig. 22d) [191, 192].

\section{Optically clean and single crystalline diamond}

Diamond's unique multispectral transparency combined with its mechanical strength, chemical inertness and 
(a)
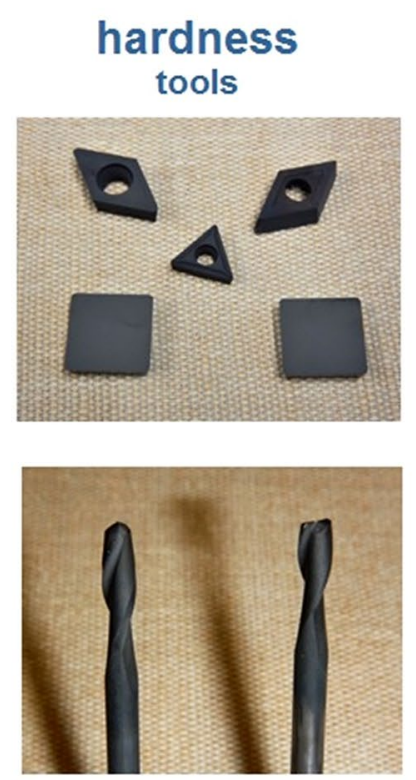

(b)

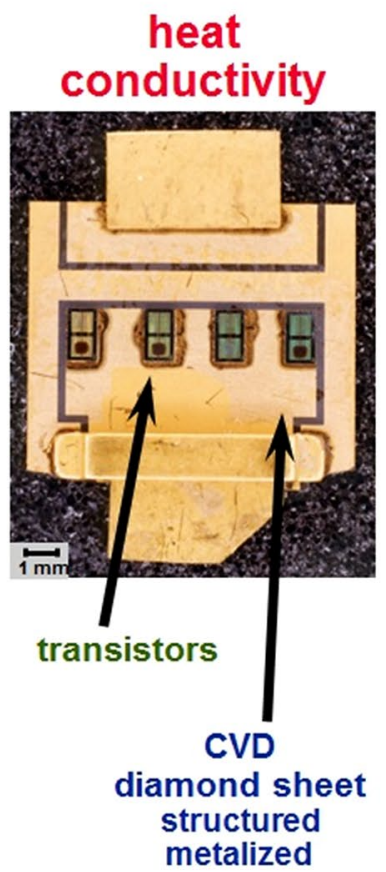

(c)

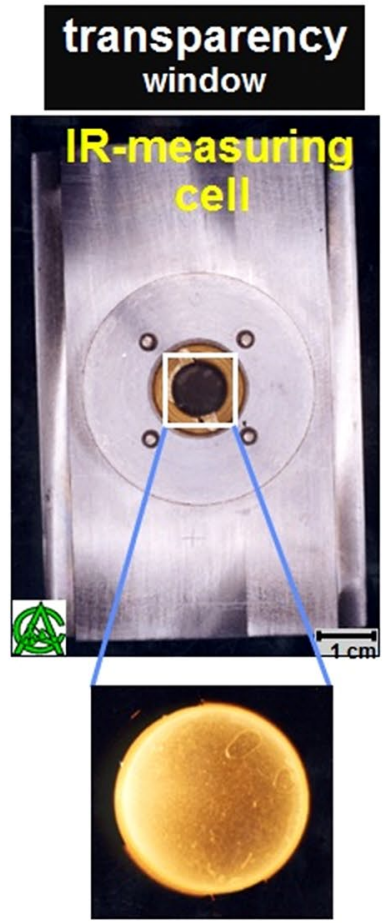

(d)

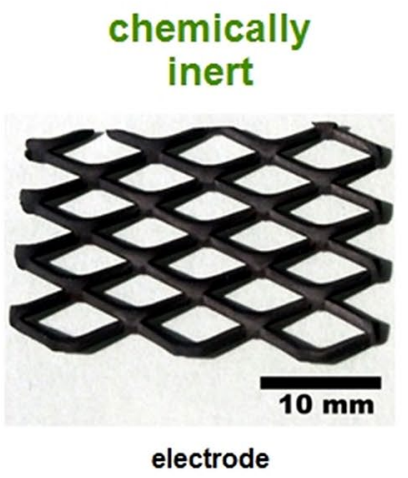

B-doped diamond on $\mathrm{Ti}$

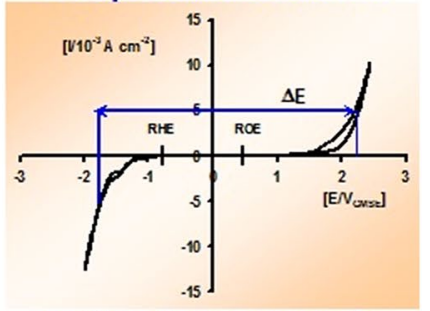

cyclovoltamogramm in

Fig. 22 Areas of application for CVD diamond that have been implemented industrially for a hard coatings on tools, $\mathbf{b}$ diamond sheets as heat sinks, $\mathbf{c}$ transparent diamond windows, $\mathbf{d}$ chemically inert diamond electrodes for electrochemical applications

abrasion resistance makes it a desirable material for optical windows (Fig. 22c).

Examples for the usage of CVD diamond windows are: X-ray detector windows for SEM and X-ray tubes [193, 194], mid-infrared attenuated total reflectance (ATR) spectroscopy [195] or optical diamond lenses [196].

Growth of single crystalline diamond requires a single crystalline seed crystal and growth rates are usually low to avoid defects and impurities in the diamonds [197]. CVD grown and polished gemstones up to several carats in weight are available and used in jewellery [198, 199].

If you consider the initial scepticism about CVD diamond deposition, the economic production of diamond single crystals for jewellery is certainly a high point of diamond research.

\section{Knowledge on CVD diamond deposition is disappearing}

It should not be possible for published knowledge to get lost, so why does this happen?

About 40 years ago scientists invented the low-pressure diamond deposition, and they found the most important deposition parameters and developed the theories for CVD diamond growth. These scientists are mostly retired and no longer working.

The large hype around diamond deposition was in the 1990s where many universities, research centres and companies were interested in new diamond applications. Over time, large companies took over the development of diamond products, start-ups were created for smaller areas of application and, as a result of a lack of funding, university research decreased. With university research, however, university teaching also disappeared.

Some long-established scientists can still understand the fascination of diamond synthesis at the time, but today this fascination has given way to indifference.

CVD diamond is manufactured in "black box" plants, the parameters are set, and it is not necessary to understand the chemical reactions at the plant. These are the circumstances in which the knowledge and secrets of CVD diamond deposition are lost.

An admittedly additional difficulty is that in the 1990s, the scientific work was not and is not digitally available, which of course means an increased effort for its procurement.

There is hope that this manuscript will be a useful summary of the history of CVD diamond deposition and that the essential secrets of diamond deposition will not be forgotten. 
Funding Open access funding provided by TU Wien (TUW).

Open Access This article is licensed under a Creative Commons Attribution 4.0 International License, which permits use, sharing, adaptation, distribution and reproduction in any medium or format, as long as you give appropriate credit to the original author(s) and the source, provide a link to the Creative Commons licence, and indicate if changes were made. The images or other third party material in this article are included in the article's Creative Commons licence, unless indicated otherwise in a credit line to the material. If material is not included in the article's Creative Commons licence and your intended use is not permitted by statutory regulation or exceeds the permitted use, you will need to obtain permission directly from the copyright holder. To view a copy of this licence, visit http://creativecommons.org/licenses/by/4.0/.

\section{References}

1. Bundy FP, Hall HT, Strong HM, Wentorf RH (1955) Man-made diamonds. Nature 176:51-56

2. Spitsyn BV, Deryaguin BV (1956) Method of growing diamond faces (in Russian). USSR author's certificate No. 339134, Appl. $964957 / 716358$

3. Eversole WG (1958)Synthesis of diamond. US Patents NN 3030187 and 3030188

4. Spitsyn BV (1966) Ph.D. Thesis, Inst. Phys. Chem. RAS, Moscow (in Russian)

5. Deryagin BV, Fedoseev DV, Lukyanovich VM, Spitsyn BV, Ryanov AV, Lavrentyev AV (1968) J Cryst Growth 2:380

6. Angus JC, Will HA, Stanko WS (1968) Growth of diamond seed crystals by vapour deposition. J Appl Phys 39:2915-2922

7. Derjaguin BV (1969) New Scientist 44:228 (in Russian)

8. Deryaguin BV, Fedoseev DV (1970) Usp Khim 39:1661 (in Russian)

9. Deryagin BV, Spitsyn BV, Fedoseev DV, Ryabov VA, Bochko AV, Lavrent'ev AV (1971) Fiz -Khim Probl Kristalliz 2:90 (in Russian)

10. Deryaguin BV, Fedoseev DV, Bakul' VN, Ryabov VA, Spitsyn BV, Nikitin YI, Bochko AV, Varnin VP, Lavrent'ev AV, Primachuk VL (1971) Physical-chemical synthesis of diamond from vapor phase. Tekhnika, Kiev (in Russian)

11. Derjaguin BV, Spitsyn BV, Aleksenko AE, Gorodetsky AE, Zakharov AP, Nazarova RI (1973) Dokl Akad Nauk USSR 213:1059 (in Russian)

12. Deryagin BV, Spitsyn BV, Builov LL, Klochov AA, Gorodetskii AE, Smol'yanimov AV (1976) Dokl Akad Nauk SSSR 231:333 (in Russian)

13. Derjaguin BV, Spitsyn BV, Gorodetsky AE, Zakharov AP, Bouilov LL, Aleksenko AE (1975) Structure of autoepitaxial diamond films. J Cryst Growth 31:44-48

14. Spitsyn BV, Builov LL, Deryagin BV (1981) Vapor growth of diamond on diamond and other substrates. J Cryst Growth 52:219-226

15. Gautherin G, Chr W (1978) Some trends in preparing film structures by ion beam methods. Thin Solid Films 50:135-144

16. Chr W, Schürer C, Fröhlich F, Grau P, Lehmann H (1979) Mechanical properties of hard carbon films. Thin Solid Films 61:15-17

17. Chr W, Bewilogua K, Schürer C, Breuer K, Zscheile H (1979) Characterization of hard carbon films by electron energy loss spectrometry. Thin Solid Films 61:11-14
18. Weissmantel C, Bewilogua K, Dietrich D, Erler HJ, Hinnerberg H, Klose S, Nowick W, Reisse G (1980) Structure and properties of quasi-amorphous films prepared by ion beam techniques. Thin Solid Films 72:19-32

19. Bewilogua K, Hofmann D (2014) History of diamond-like carbon films-from first experiments to worldwide applications. Surf Coat Technol 242:214-225

20. Matsumoto S, Sato Y, Setaka N (1982) Vapour deposition of diamond particles from methane Part 2. Jpn J Appl Phys 21:183-187

21. Matsumoto S, Sato Y, Tsutsumi M, Setaka N (1982) Growth of diamond particles from methane-hydrogen gas. J Mater Sci 17:3106-3112

22. Matsumoto S, Matsui Y (1983) Electron microscopic observation of diamond particles grown from the vapour phase. J Materials Sci 18:1785-1793

23. Kamo M, Sato Y, Matsumoto S, Setaka N (1983) Diamond synthesis from gas phase by decomposition of methane in microwave plasma. J Cryst Growth 62:642-646

24. Schubert WD, Haubner R, Danninger H, Zeiler B, Lassner E, Ortner H (2006) Editorial, Special Issue devoted to the 75th birthday of Em. O.Univ. Prof. Dipl.-Ing. Dr.techn. Benno Lux. Int J Refract Metals Hard Mater 24:351-352

25. Bichler R (1985) Abscheidung von kristallinem Kohlenstoff aus Methan-Wasserstoffgemischen (Deposition of crystalline carbon from methane-hydrogen mixtures). TU Wien, Diploma Thesis (in German)

26. Bichler R, Haubner R, Lux B (1987) Low pressure diamond deposition from a methane-hydrogen gas mixture. 6th Euro CVD Conf., Jerusalem 413-22

27. Bichler R, Haubner R, Lux B (1989) Diamantabscheidung aus Wasserstoff-Methan Gasgemischen mittels thermisch aktivierter Gasabscheidung (TA-CVD) auf SiAlON-Substraten (Diamond deposition from hydrogen-methane gas mixtures using thermally activated gas deposition (TA-CVD) on SiAlON substrates). High Temp High Press 21:576-593 (in German)

28. Badzian A, Badzian T (1993) Diamond homoepitaxy by chemical vapour deposition. Diam Relat Mater 2:147-157

29. Lux B, Haubner R (1989) Low pressure synthesis of superhard coatings. Int J Refract Metals Hard Mater 8:158-174

30. Volmer M, Weber A (1925) Keimbildung in übersättigten Gebilden. Z Phys Chem 119:277 (in German)

31. Litos R, Haubner R, Lux B (1990) Untersuchung der Kinetik von Diamantabscheidungen auf Mo-Drahtsubstraten (Investigation of the kinetics of diamond deposits on Mo wire substrates). High Temp High Press 22:99-118 ((in German))

32. Butler JE, Celii FG, Oakes DB, Hanssen LM, Carrington WA, Snail KA (1990) Studies of diamond chemical vapor deposition. High Temp Sci 27:183-197

33. Celii FG, Pehrsson PE, Wang HT, Butler JE (1988) Infrared detection of gaseous species during the filament-assisted growth of diamond. Appl Phys Lett 52:2043-2045

34. Celii FG, Pehrsson PE, Wans HT, Nelson HH, Butler JE (1990) In-situ detection of gaseous species in the filament-assisted diamond growth environment. In: Saito S, Fukunaga O, Yoshikawa M (eds) Science and technology of new diamond. KTK Scientific/Terra Scientific, Tokyo, pp 17-23

35. Battaile C, Srolovitz DJ, Butler JE (1997) 3-D atomistic kinetic Monte Carlo simulations of point defect incorporat ion during CVD diamond film growth. Mater Res Soc Symp Proc 441:509-514

36. Schwärzler CG, Schnabl O, Laimer J, Störi H (1996) On the plasma chemistry of the $\mathrm{C} / \mathrm{H}$ system relevant to diamond deposition processes. Plasma Chem Plasma Process 16:173-185

37. Lang T, Laimer J, Störi H (1994) Quasi-equilibria of gaseous species in the CH system. Diam Relat Mater 3:470-475 
38. Butler JE, Mankelevich YA, Cheesman A, Jie Ma, Ashfold MNR (2009) Understanding the chemical vapor deposition of diamond: recent progress. J Phys Condens Matter 21:364201-364221

39. Lux B, Haubner R, Holzer H, DeVries RC (1997) Natural and synthetic polycrystalline diamond, with emphasis on ballas. Int J Refract Metals Hard Mater 15:263-288

40. Bühlmann S, Blank E, Haubner R, Lux B (1999) Characterization of ballas diamond depositions. Diam Relat Mater 8:194-201

41. Barnes PN, Wu RLC (1993) Nucleation enhancement of diamond with amorphous films. Appl Phys Lett 62:37-39

42. Bachmann PK, Wiechert DU (1991) Characterization and properties of artificially grown diamond. In: Clausing RE, Horton LL, Angus JC, Koidl P (eds) Diamond and diamond-like films and coatings. Plenum, New York, pp 677-713

43. Haubner R, Lux B (1987) Influence of Inhomogeneous microwave plasma on diamond morphology. Int J Refract Metals Hard Mater 6:210-215

44. Lindlbauer A, Haubner R, Lux B (1992) Effects of microwave plasma deposition parameters on diamond coating formation on SiAlON substrates. Int J Refract Metals Hard Mater 11:247-258

45. Lindlbauer A (1992) Keimbildung und Wachstum von Diamant mit Mikrowellen-Plasma (Nucleation and growth of diamond with microwave plasma). Doctoral Thesis at TU Wien (in German)

46. Litos R (1992) Herstellung von Diamantpulvern mit verschiedenen Niederdruck-CVD-Verfahren (Production of diamond powders using various low-pressure CVD processes). Doctoral Thesis at TU Wien (in German)

47. Haubner R, Lux B (1993) Diamond growth by hot-filament CVD: state of the art. Diam Relat Mater 2:1277-1294

48. Satrapa D, Haubner R, Lux B (1994) A simple method to calculate the temperature distribution in hot-filament CVD reactors. Diamond Films Technol 4:201-217

49. Okoli S, Haubner R, Lux B (1991) Influence of the filament material on low-pressure hot-filament CVD diamond deposition. J Phys IV 02:C2-923-C2-930

50. Okoli S, Haubner R, Lux B (1991) Carburization of tungsten and tantalum filaments during low-pressure diamond deposition. Surf Coat Technol 47:585-599

51. Sommer M, Mui K, Smith FW (1989) Thermodynamic analysis of the chemical vapor deposition of diamond films. Solid State Commun 69:775-778

52. Lux B, Haubner R (1993) Diamond as a wear-resistant coating. Phil Trans R Soc Lond A 342:297-311

53. Roy M, Haubner R (2013) Diamond film and their tribological performances. In: Roy M (ed) Surface engineering for enhanced performance against wear. Springer, Wien, pp 79-110

54. CemeCon. https://www.cemecon.de/en/coating-systems. Accessed Nov 2020

55. SP3 Diamond Technologies. https://www.sp3diamondtech.com/. Accessed Nov 2020

56. Seki Diamond Systems. Hot filament diamond CVD systems. http://sekidiamond.com/hot-filament-cvd-systems/. Accessed Nov 2020

57. Hanssen LM, Carrington WA, Butler JE, Snail KA (1988) Diamond synthesis using an oxygen-acetylene torch. Mater Lett 7:289-292

58. Brunsteiner R (1994) Untersuchung der Diamantabscheidung mit den Methoden Hot Filament, Acetylenflamme und DCGlimmentladung (Investigation of diamond deposition using the hot-filament, acetylene flame and DC glow-discharge methods). Doctoral Thesis at TU Wien (in German)

59. Füner M, Wild C, Koidl P (1995) Numerical simulations of microwave plasma reactors for diamond CVD. Surf Coat Technol 74-75:221-226
60. Wörner E, Pleuler E, Wild C, Koidl P (2003) Thermal and optical properties of high purity CVD-diamond discs doped with boron and nitrogen. Diam Relat Mater 12:744-748

61. Seki Diamond Systems. Microwave plasma CVD systems. http:// sekidiamond.com/microwave-plasma-cvd-systems/. Accessed Nov 2020

62. iplas. CYRANNUS. http://www.iplas.de/. Accessed Nov 2020

63. Karner J, Bergmann E, Daxinger H (1994) Plasma CVD method for producing a diamond coating. US Patent 5616373

64. Karner J, Pedrazzini M, Hollenstein C (1996) High current d.c. arc (HCDCA) technique for diamond deposition. Diam Relat Mater 5:217-220

65. Kalss W, Reiter A, Derflinger V, Gey C, Endrino JL (2006) Modern coatings in high performance cutting applications. Int $\mathrm{J}$ Refract Metals Hard Mater 24:399-404

66. Cappelli MA, Owano TG (1998) Plasma-Jet deposition of diamond. In: Dischler B, Wild C (eds) Low pressure synthetic diamond. Springer-Verlag, Berlin, Chap 4, pp 59-84

67. Laimer J, Pauser H, Schwärzler CG, Störi H (1998) Direct-current low-pressure supersonic plasma jet used for diamond deposition. Surf Coat Technol 98:1066-1071

68. Laimer J, Pauser H, Störi H, Haubner R, Lux B (1997) Diamond growth in a direct-current low-pressure supersonic plasmajet. Diam Relat Mater 6:406-410

69. Lugscheider E, Müller U (1993) Evaluation of d.c.-plasma jet chemical vapour deposition for diamond coatings on tungsten carbide based cutting plates. Diam Relat Mater 2:1464-1466

70. Satrapa D, Haubner R, Lux B (1991) Aspects of diamond deposition by abnormal glow discharge-(DC-discharge-)activated CVD. Surf Coat Technol 47:59-68

71. Hartmann P, Haubner R, Lux B (1998) Characteristics of a pulsed DC-glow discharge CVD reactor for deposition of thick diamond films. J Int Refract Met Hard Mat 16:207-216

72. Hartmann P, Haubner R, Lux B (1996) Deposition of thick diamond films by pulsed d.c. glow discharge CVD. Diam Relat Mater 5:850-856

73. Haubner R (2006) Diamond layers-deposition methods and applications. in: Proceedings 15th IFHTSE, Vienna, 322-327

74. Bachmann PK, Leers D, Lvdtin H (1991) Towards a general concept of diamond chemical vapour deposition. Diam Relat Mater $1: 1-12$

75. Schwarzbach D, Haubner R, Lux B (1994) Internal stresses in diamond CVD layers. Diam Relat Mater 3:757-764

76. Joksch M, Wurzinger P, Pongratz P, Haubner R, Lux B (1994) Characterization of diamond coatings with transmission electron microscopy (TEM). Diam Relat Mater 3:681-687

77. Wild C, Koidl P, Herres N, Müller-Sebert W, Eckermann T (1991) Textured growth and twinning in polycrystalline CVD diamond films. In: Purdes AJ et al (eds) 2nd Int Symp Diamond Materials Proceedings. Pennington, NJ: The Electrochem Soc 224-239

78. Wild C, Herres N, Koidl P (1990) Texture formation in polycrystalline diamond films. J Appl Phys 68:973-978

79. Gruen DM (2001) Growth of nanocrystalline diamond films. In: Nazare MH, Neves AJ (eds) Properties, growth and application of diamond. INSPEC, London, pp 299-302

80. Williams OA, Nesladek M (2006) Growth and properties of nanocrystalline diamond films. Phys Status Solidi A 203:3375-3386

81. Gruen DM (2001) Nucleation of ultrananocrystalline diamond films. In: Nazare MH, Neves AJ (eds) Properties, growth and application of diamond. INSPEC, London, pp 303-306

82. Williams OA, Daenen M, D’Haen J, Haenen K, Maes J, Moshchalkov VV, Nesladek M, Gruen DM (2006) Comparison of the growth and properties of ultrananocrystalline diamond and nanocrystalline diamond. Diam Relat Mater 15:654-658 
83. Haubner R, Lux B (2002) Deposition of ballas diamond and nano-crystalline diamond. J Int Refract Met Hard Mat 20:93-100

84. Brunsteiner R, Haubner R, Lux B (1993) Hot-filament CVD diamond deposition on SiAlON at pressures up to 500 torr. Diam Relat Mater 2:1263-1270

85. Haubner R, Okoli S, Lux B (1992) The importance of the substrate surface temperature and other parameters in hot-filament diamond synthesis. Int J Refract Metals Hard Mater 11:259-269

86. Okoli S, Haubner R, Lux B (1989) Acetone as carbon source for deposition of diamond thin films by thermal CVD. J Phys Coll. C5, suppl.5, 159-68

87. Brunsteiner R, Haubner R, Lux B (1996) Influence of carbon monoxide-addition to the reaction gas on the hot-filament diamond deposition. Int J Refract Metals Hard Mater 14:127-135

88. Hartmann P, Bohr S, Haubner R, Lux B, Wurzinger P, Griesser M, Bergmaier A, Dollinger G, Sternschulte H, Sauer R (1998) Diamond growth with boron addition. Int J Refract Metals Hard Mater 16:223-232

89. Fujimori N, Nakahata H, Imai T (1990) Properties of borondoped epitaxial diamond films. Jpn J Appl Phys 29:824-827

90. Okano K, Akiba Y, Kurosu T, Iida M, Nakamura T (1990) Synthesis of B-doped diamond film. J Cryst Growth 99:1192-1195

91. Boettger E, Bluhm A, Jiang X, Schäfer L, Klages C-P (1995) Investigation of the high-field conductivity and dielectric strength of nitrogen containing polycrystalline diamond films. J Appl Phys 77:6332-6337

92. Wörner E, Wild C, Müller-Sebert W, Locher R, Koidl P (1996) Thermal conductivity of CVD diamond films: high-precision, temperature-resolved measurements. Diam Relat Mater 5:688-692

93. Bohr S, Haubner R, Lux B (1996) Influence of nitrogen addition on hot-filament CVD diamond growth. Appl Phys Lett 68:1075-1077

94. Bohr S, Haubner R, Lux B (1995) Influence of phosphorus addition on diamond CVD. Diam Relat Mater 4:133-144

95. Fujimori N, Imai T, Nakahata H, Shiomi H, Nishibayashi Y (1990) Mat Res Soc Symp Proc 162:23-33

96. Kamo M, Yurimoto H, Ando T, Sato Y (1990) In: Messier R, Glass JT, Butler JE, Roy R (eds) New diamond science and technology. MRS Int Conf Proc, Washington DC, pp 637-641

97. Sachdev H, Haubner R, Lux B (1997) Lithium addition during CVD diamond deposition using lithium tert-butanolat as precursor. Diam Relat Mater 6:494-500

98. Sternschulte H, Schreck M, Stritzker B, Bergmaier A, Dollinger $G$ (2000) Lithium addition during CVD diamond growth: influence on the optical emission of the plasma and properties of the films. Diam Relat Mater 9:1046-1050

99. Barber GD, Yarbrough WA (1997) Growth rate of diamond on polycrystalline $<110\rangle$ diamond substrates from carbon disulfide in hydrogen by hot-filament-assisted chemical vapor deposition. J Am Ceram Soc 80:1560-1566

100. Haubner R, Sommer D (2003) Hot-filament diamond deposition with sulfur addition. Diam Relat Mater 12:298-305

101. Haubner R (2004) Diamond deposition with sulfur addition-thermodynamic calculations. Diam Relat Mater 13:648-655

102. Shiomi H, Nakahata H, Imai T, Nishibayshi Y, Fujimori N (1989) Electrical characteristics of metal contacts to borondoped diamond epitaxial film. Jap J Appl Phys 28:758-762

103. Mort J, Kuhman D, Machonkin M, Morgan M, Jansen F, Okumura K, LeGrice YM, Nemanich RJ (1989) Boron doping of diamond thin films. Appl Phys Lett 55:1121-1123

104. Fujimori N, Nishibayashi Y (1992) Diamond devices made of epitaxial diamond films. Diam Relat Mater 1:665-668

105. Gerger I, Haubner R, Kronberger H, Fafilek G (2004) Investigation of diamond coatings on titanium substrates for electrochemical applications. Diam Relat Mater 13:1062-1069
106. Weissenbacher R, Haubner R, Aigner K, Lux B (2002) Interactions of Ta-filaments during hot-filament CVD of BCN-layers. Diam Relat Mater 11:191-197

107. Wang XH, Ma G-H, Wie Z, Glass JT, Bergman L, Turner KF, Nemanich RJ (1992) Effects of boron doping on the surface morphology and structural imperfections of diamond films. Diam Relat Mater 1:828-835

108. Liao XZ, Zhang RJ, Lee CS, Tong Lee S, Lam YW (1997) The influence of boron doping on the structure and characteristics of diamond thin films. Diam Relat Mater 6:521-525

109. Wurzinger P, Pongratz P, Hartmann P, Haubner R, Lux B (1997) Investigation of the boron incorporporation in polycrystalline CVD diamond films by TEM, EELS and Raman spectroscopy. Diam Relat Mater 6:763-768

110. Kolber T, Piblits K, Haubner R, Hutter H (1999) Quantitative investigation of boron incorporation in polycrystalline CVD diamond films by SIMS. Fresenius J Anal Chem 365:636-641

111. Haubner R, Bohr S, Lux B (1999) Comparison of P, N and B additions during CVD diamond deposition. Diam Relat Mater 8:171-178

112. Spitsyn BV, Alexenko AE (1991) Proc Electrochem Soc 91-8:597-604

113. Okano K, Kiyota H, Iwasaki T, Nakamura Y, Akiba Y, Kuroso T, Iida M, Nakamura T (1990) Synthesis of n-type semiconducting diamond film using diphosphorus pentaoxide as the doping source. Appl Phys A 51:344-346

114. Haubner R, Lux B (1989) Influence of a nitrogen gas content on the deposition of low-pressure diamond layers by the hot filament CVD-method. In: Sudarshan TS, Bhat DG (eds) 3rd Int Conf Surface Modification Technologies, Neuchatel, Switzerland, pp 835-839

115. Jin S, Moustakas TD (1994) Effect of nitrogen on the growth of diamond films. Appl Phys Lett 65:403-405

116. Mort J, Machonkin MA, Okumura K (1991) Compensation effects in nitrogen doped diamond thin films. Appl Phys Lett 59:3148-3150

117. Fujimori N, Ikegaya A, Imai T, Ota N, Shibata T (1991) Chemical vapor deposition method of high quality diamond. Eur Patent Application EP0469626A2

118. Nishitani-Gamo M, Yasu E, Xiao C, Kikuchi Y, Ushizawa K, Sakaguchi I, Suzuki T, Ando T (2000) Sulfur-doped homoepitaxial (001) diamond with n-type semiconductive properties. Diam Relat Mater 9:941-947

119. Nishitani-Gamo M, Xiao C, Zhang Y, Yasu E, Kikuchi Y, Sakaguchi I, Suzuki T, Ando T (2001) Homoepitaxial diamond growth with sulfur-doping by microwave plasma-assisted chemical vapor deposition. Thin Solid Films 382:113-123

120. Sternschulte H, Schreck M, Stritzker B (2002) In situ characterisation of CVD diamond growth under $\mathrm{H}_{2} \mathrm{~S}$ addition by optical emission spectroscopy, mass spectroscopy and laser reflection interferometry. Diam Relat Mater 11:296-300

121. Petherbridge JR, May PW, Fuge GM, Rosser KN, Ashfold MNR (2002) In situ plasma diagnostics of the chemistry behind sulfur doping of CVD diamond films. Diam Relat Mater 11:301-306

122. Hartmann P, Haubner R, Lux B (1997) Effects of simultaneous boron and nitrogen addition on hot-filament CVD diamond growth. Diam Relat Mater 6:456-462

123. Joffreau PO, Bichler R, Haubner R, Lux B (1988) Low-pressure diamond growth on high-pressure diamond crystals pressed onto different substrates. Int J Refract Metals Hard Mater 7:92-97

124. Haubner R (1990) Deposition of thermal CVD low-pressure diamond on cub-BN. Int J Refract Metals Hard Mater 9:70-76

125. Kalss W, Haubner R, Lux B (1997) Diamond deposition on noble metals. Diam Relat Mater 6:240-246 
126. Joffreau PO, Haubner R, Lux B (1988) Low-pressure diamond growth on different refracteric metals. Int J Refract Metals Hard Mater 7:186-194

127. Haubner R, Lindlbauer A, Lux B (1996) Diamond nucleation and growth on refractory metals using microwave plasma deposition. Int J Refract Metals Hard Mater 14:119-125

128. Ullrich HJ, Schlaubitz M, Haubner R, Lux B (1992) Radiation analytical material characterization of diamond layers deposited onto tungsten carbide. Microchem Acta 107:257-263

129. Yugo S, Izumi A, Kanai T, Muto T, Kimura T (1991) Some observations of nucleation sites in diamond growth by plasma CVD. Proceedings of the 2nd international conference on new diamond science and technology, pp 385-389

130. Yugo S, Kimura T, Kanai T (1993) Nucleation mechanisms of diamond in plasma chemical vapor deposition. Diam Relat Mater 2:328-332

131. Lindlbauer A, Haubner R, Lux B (1992) Low-pressure diamond deposition on iron substrates by microwave-plasma CVD. Diamond Films Technol 2:81-98

132. Haubner R, Lindlbauer A, Lux B (1993) Diamond deposition on chromium, cobalt and nickel substrates by microwave plasma CVD. Diam Relat Mater 2:1505-1515

133. Haubner R, Lux B, Gruber U, Schuster JC (1999) Diamond deposition on $\mathrm{Ni}_{3} \mathrm{Ge}$ single- and polycrystalline substrates. Diam Relat Mater 8:246-250

134. Kalss W, Haubner R, Lippold G, Lux B (1998) Diamond deposition on platinum and palladium-Raman investigations. Diam Relat Mater 7:158-164

135. Lindlbauer A, Haubner R, Lux B (1992) Diamantabscheidung auf keramischen Materialien mit der Hot-Filament-Methode. Wear 159:67-77

136. Haubner R, Lessiak M (2015) Diamond coatings on carbon based substrates. Mater Sci Forum 825-826:605-612

137. Haubner R, Lessiak M (2017) Deposition of CVD diamond coatings on carbon fiber composite substrates. Key Eng Mater 742:419-426

138. Jiang X, Klages C-P (1993) Heteroepitaxial diamond growth on (100) silicon. Diam Relat Mater 2:1112-1113

139. Jiang X, Klages C-P (1996) Heteroepitaxy of diamond on silicon. Ceram Int 22:443-448

140. Schreck M, Gsell S, Brescia R, Fischer M (2017) Ion bombardment induced buried lateral growth: the key mechanism for the synthesis of single crystal diamond wafers. Sci Rep 7:44462

141. Lassner E, Schubert WD (1999) Tungsten. Kluwer Academic/ Plenum, New York

142. Haubner R, Lux B (1996) On the formation of diamond coatings on WC/Co hard metal tools. Int J Refract Metals Hard Mater 14:111-118

143. Haubner R, Lux B (1989) Influence of the cobalt content in hotpressed cemented carbide on the deposition of low pressure diamond layers. J Phys Coll.C5, suppl.5, 169-76

144. Kubelka S, Haubner R, Lux B, Steiner R, Stingeder G, Grasserbauer M (1994) Influences of WC-Co hard metal substrate pretreatments with boron and silicon on low pressure diamond deposition. Diam Relat Mater 3:1360-1369

145. Haubner R, Schubert WD, Lux B (1998) Interactions of hard metal substrates during diamond deposition. Int J Refract Metals Hard Mater 16:177-185

146. Huang TH, Kuo CT, Chang CS, Kao CT, Wen HY (1992) Tribological behaviours of the diamond-coated cemented carbide tools with various cobalt contents. Diam Relat Mater 1:594-599

147. Mehlmann AK, Dirnfeld SF, Avigal Y (1992) Investigation of low-pressure diamond deposition on cemented carbides. Diam Relat Mater 1:600-604

148. Kubelka S, Haubner R, Lux B, Steiner R, Stingeder G, Grasserbauer M (1995) Chemical interactions of WC/Co hard metal substrates with low-pressure diamond coatings. Diamond Films Technol 5:105-120

149. Shibuki K, Yagi M, Saijo K, Takatsu S (1988) Adhesion strength of diamond films on cemented carbide substrates. Surf Coat Technol 36:295-302

150. Pan XX (1989) Verbesserung von Reproduzierbarkeit und Haftung bei der Diamantabscheidung auf kommerziell verfügbaren WC-Co-Hartmetallen (Improvement of reproducibility and adhesion in diamond deposition on commercially available WC-Co hardmetals). Doctoral Thesis, TU Wien (in German)

151. Peters MG, Cummings RH (1992) European Patent Nr. 0519587A1

152. Haubner R, Kubelka S, Lux B, Griesser M, Grasserbauer M (1995) Murakami and $\mathrm{H}_{2} \mathrm{SO}_{4} / \mathrm{H}_{2} \mathrm{O}_{2}$ pretreatment of WC-Co hard metal substrates to increase the adhesion of CVD diamond coatings. J Phys IV 05:C5-753-C5-760

153. Köpf A, Haubner R, Lux B (2002) Multilayer coatings containing diamond and other hard materials on hardmetal substrates. Int $\mathrm{J}$ Refract Metals Hard Mater 20:107-114

154. Lessiak M, Haubner R (2013) Diamond coatings on hardmetal substrates with CVD coatings as intermediate layers. Surf Coat Technol 230:119-123

155. Ullram S, Haubner R (2006) Temperature pre-treatments of hardmetal substrates to reduce the cobalt content and improve diamond deposition. Diam Relat Mater 15:994-999

156. Haubner R, Ullram $\mathrm{S}$ (2008) Influence of $\mathrm{H}_{2} \mathrm{~S}$ addition during diamond deposition on hardmetal substrates. Diam Relat Mater 17:1100-1105

157. Haubner R, Köpf A, Lux B (2002) Diamond deposition on hardmetal substrates after pre-treatment with boron or sulfur compounds. Diam Relat Mater 11:555-561

158. Sommer M, Haubner R, Lux B (2000) Diamond deposition on copper treated hardmetal substrates. Diam Relat Mater 9:351-357

159. Köpf A, Sommer M, Haubner R, Lux B (2001) Diamond deposition on hardmetal-substrates after pre-treatment with aluminium or aluminium-compounds. Diam Relat Mater 10:790-796

160. Köpf A, Haubner R, Lux B (2000) Double-layer coatings on WC-Co hardmetals containing diamond and titaniumcarbide/ nitride. Diam Relat Mater 9:494-501

161. Haubner R, Lux B (2006) Diamond deposition on steel substrates using intermediate layers. Int J Refract Metals Hard Mater 24:380-386

162. Fayer A, Glozman O, Hoffman A (1995) Deposition of continuous and well adhering diamond films on steel. Appl Phys Lett 67:2299-2301

163. Rudigier M, Haubner R (2012) Characterisation of diamond coatings with different morphologies by Raman spectroscopy using various laser wavelengths. Anal Bioanal Chem 403:675-681

164. Haubner R, Rudigier M (2013) Raman characterisation of diamond coatings using different laser wavelengths. Phys Proc 46:71-78

165. Griesser M, Grasserbauer M, Kellner R, Bohr S, Haubner R, Lux B (1995) NIR- and VIS-Raman spectroscopy of CVD diamond films. Fresenius J Anal Chem 352:763-770

166. Lux B, Haubner R, Griesser M, Grasserbauer M (1997) Superhard coatings-production and analysis. Microchim Acta 125:197-209

167. Wagner W, Rauch F, Haubner R, Lux B (1992) Analysis of hydrogen in low pressure diamond layers. Thin Solid Films 207:24-28

168. Kalss W, Bohr S, Haubner R, Lux B, Griesser M, Spicka H, Grasserbauer M, Wurzinger P (1996) Influence of boron on diamond growth on WC-Co hardmetals. Int J Refract Metals Hard Mater 14:137-144 
169. Griesser M, Stingeder G, Grasserbauer M, Baumann H, Wurzinger P, Haubner R, Lux B (1994) Characterization of tantalum impurities in hot-filament diamond layers. Diam Relat Mater 3:638-644

170. Spicka H, Griesser M, Hutter H, Grasserbauer M, Bohr S, Haubner R, Lux B (1996) Investigation of the incorporation of B, P and $\mathrm{N}$ into CVD-diamond films by secondary ion mass spectrometry. Diam Relat Mater 5:383-387

171. Ponahlo J, Haubner R, Lux B (1994) Cathodoluminescence (CL) and CL spectra of microwave plasma enhanced CVD diamond. Microchim Acta 116:143-156

172. Koizumi S, Umezawa H, Pernot J, Suzuki M (eds) (2018) Power electronics device applications of diamond semiconductors. Woodhead, Duxford

173. Ekimov EA, Sidorov VA, Bauer ED, Mel'nik NN, Curro NJ, Thompson JD, Stishov SM (2004) Superconductivity in diamond. Nature 428:542-545

174. Lee K-W, Pickett WE (2004) Superconductivity in boron-doped diamond. Phys Rev Lett 93:237003

175. Waldermann FC, Olivero P, Nunn J, Surmacz K, Wang ZY, Jaksch D, Taylor RA, Walmsley IA, Draganski M, Reichart P, Greentree AD, Jamieson DN, Prawer S (2007) Creating diamond color centers for quantum optical applications. Diam Relat Mater 16:1887-1895

176. Oakes J, Pan XX, Haubner R, Lux B (1991) Chemical vapour deposition diamond coatings on cemented carbide tools. Surf Coat Technol 47:600-607

177. Lux B, Haubner R (1998) CVD diamond for cutting tools. In: Dischler B, Wild C (eds) Low pressure synthetic diamond. Springer-Verlag, Berlin, pp 223-242

178. Lux B, Haubner R, Renard P (1992) Diamond for tooling and abrasives. Diam Relat Mater 1:1035-1047

179. Lux B, Haubner R (1996) Diamond deposition on cutting tools. Ceramic Int 22:347-351

180. Haubner R, Kalss W (2010) Diamond deposition on hardmetal substrates-comparison of substrate pre-treatments and industrial applications. Int J Refract Metals Hard Mater 28:475-483

181. Oerlikon. BALINIT wear protection through thin-film coating. https://www.oerlikon.com/balzers/com/en/portfolio/balzers-surfa ce-solutions/pvd-and-pacvd-based-coatings/balinit/. Accessed Nov 2020

182. Boehlerit. Diamond mini cut. https://www.boehlerit.com/filea dmin/user_upload/PDF/Diamond_Mini_Cut.pdf. Accessed Nov 2020

183. CemeCon. https://www.cemecon.de/de/schichtwerkstoffe. Accessed Nov 2020

184. Roy M, Vorlaufer G, Pauschitz A, Haubner R (2010) Effect of morphology of diamond films on friction response in reciprocating sliding at milli-newton loads. J Tribol Surface Eng 1:185-202

185. Roy M, Haubner R (2010) Tribology of hard coatings. Int J Refract Metals Hard Mater 28:1
186. Holzer H (1996) CVD Diamantträger für elektronische Bauelemente (CVD diamond carriers for electronic components). Doctoral Thesis at TU Wien (in German)

187. Holzer H, Haubner R, Lux B (1996) Mechanical and thermal applications of low-pressure diamond. In: Manfredotti C, Vittone E (eds) Conference proceedings Vol. 52 "EURODIAMOND '96', SIF, Bologna, pp 71-88

188. Fryda M, Matthée Th, Mulcahy S, Hampel A, Schäfer L, Tröster I (2003) Fabrication and application of Diachem ${ }^{\circledR}$ electrodes. Diam Relat Mater 12:1950-1956

189. Lévy-Clément C, Ndao NA, Katty A, Bernard M, Deneuville A, Comninellis C, Fujishima A (2003) Boron doped diamond electrodes for nitrate elimination in concentrated wastewater. Diam Relat Mater 12:606-612

190. Fryda M, Matthée Th, Mulcahy S, Höfer M, Schäfer L, Tröster I (2003) Applications of DIACHEM ${ }^{\circledR}$ electrodes in electrolytic water treatment. Electrochem Soc Interface 12:40-44

191. Gerger I, Haubner R (2006) The behaviour of Ti-substrates during diamond deposition. In: Proceedings 15th IFHTSE, pp 633-638

192. Gerger I, Haubner R (2007) Gradient layers of boron doped diamond on titanium substrates. Diam Relat Mater 16:899-904

193. Edmund Optics. II-VI optical grade polycrystalline CVD diamond windows. https://www.edmundoptics.de/f/ii-vi-opticalgrade-polycrystalline-cvd-diamond-windows/39550/. Accessed Nov 2020

194. Diamond Materials. Optische Eigenschaften von CVD-Diamant. https://www.diamond-materials.com/cvd-diamant/optisch/. Accessed Nov 2020

195. Hebei Plasma Diamond Technology. Optical windows. http:// www.hediamond.cn/en/product/23.html. Accessed Nov 2020

196. Element Six Technologies. Optics. https://e6cvd.com/media/catal og/category/Element_Six_Optical.pdf. Accessed Nov 2020

197. Gallheber B-C, Fischer M, Mayr M, Straub J, Schreck M (2018) Growth, stress, and defects of heteroepitaxial diamond on Ir/ YSZ/Si(111). J Appl Phys 123:225302

198. GIA. Laboratory-grown diamonds. https://4cs.gia.edu/en-us/ synthetic-diamond/. Accessed Nov 2020

199. International Institute of Gemology (IIG). CVD diamonds, synthetic diamonds, cultured diamonds. http://iigindia.com/ blogs/cvd-diamonds-synthetic-diamonds-cultured-diamonds/. Accessed Nov 2020

Publisher's Note Springer Nature remains neutral with regard to jurisdictional claims in published maps and institutional affiliations. 